\title{
Contribution of the transport sector to climate change mitigation: Insights from a global passenger transport model coupled with a computable general equilibrium model
}

\author{
Runsen Zhang, ${ }^{1,}$, Shinichiro Fujimori ${ }^{1}$, Hancheng Dai ${ }^{2}$, Tatsuya Hanaoka ${ }^{1}$
}

1. Center for Social and Environmental Systems Research, National Institute for Environmental Studies, 16-2 Onogawa, Tsukuba 3058506, Japan

2. College of Environmental Science and Engineering, Peking University, Beijing 100871, China

* Email: zhang.runsen@nies.go.jp; Tel.: +81-29-850-2019; Fax: +81-29-850-2422

\begin{abstract}
A passenger transport model, Asia-pacific Integrated Model (AIM)/Transport, incorporating travelers' mode of choice and transport technological details was developed in this study. This AIM/Transport was coupled with the AIM/Computable General Equilibrium (AIM/CGE) to capture interactive mechanisms between the transport sector, energy consumption, greenhouse gas (GHG) emissions, and the macro-economy. This paper presents the model structure and mathematical formulation of AIM/Transport, and explains how it was integrated with the CGE model by an iterative algorithm, taking into consideration the feedback between AIM/Transport and AIM/CGE. A numerical simulation proved that the integration of AIM/CGE and AIM/Transport can achieve a convergence after 13 iterations. A business-as-usual (BaU) scenario and a mitigation scenario were created to test the robustness of the model integration and how the mitigation potential and cost would be modified by coupling AIM/Transport. The key finding was that the carbon price and mitigation cost were modified with the coupled CGE-Transport model.
\end{abstract}

Keywords: Passenger transport; AIM/Transport; computable general equilibrium model; model integration; mitigation cost

\section{Highlights}

- Model structure and mathematical formulation of AIM/Transport

- Iterative simulation for coupling AIM/CGE and AIM/Transport

- Interaction between transport sector, energy consumption, GHG emissions, and macro-economy 


\section{Introduction}

Transport accounted for around 23\% of carbon emissions in 2013, which cannot be ignored in terms of global greenhouse gas (GHG) emissions and climate change [1]. In the transport sector, light-duty passenger vehicles are the major contributor to transport-related GHG emissions. With levels of urbanization and motorization increasing rapidly worldwide, carbon emitted in the transport sector, especially passenger traffic, is projected to keep growing [2,3]. Without the implementation of aggressive and sustained policy interventions, transport-related GHG emissions could increase at a faster rate than emissions from the energy end-use sectors, with the potential to double by 2050. Because the continuing growth in traffic activities could outweigh all mitigation measures unless transport emissions can be strongly decoupled from gross domestic product (GDP) growth, decarbonizing the transport sector will be more challenging than for other sectors $[4,5]$. It has been proposed that transport-related GHG emissions are bound up with economic development, technological change, travel behavior, transport policy, and energy efficiency improvements [2, 6-11]. Therefore, the key factors influencing global passenger transport, including travel mode and technological details, need to be taken into account to estimate long-term transport-related GHG emission pathways.

Integrated assessment models (IAMs), which integrate economic, energy, agriculture, land use, water, climate, and health factors with GHG emissions are widely used in the environmental sciences and in environmental policy analysis [12-17]. The transport sector has been taken into consideration in bottom-up integrated assessment models such as Asia-pacific Integrated Model/Enduse (AIM/Enduse), MARKAL, and the International Energy Agency (IEA) Mobility Model (MoMo) to evaluate the GHGs emitted in the transport sector [18-21]. In these models, the travel demand is computed with linear or quadratic correlations between traffic activities and GDP per capita, or an exogenously determined modal share, and therefore it is not suitable to incorporate behavioral and technological factors to assess their influences on passenger transport and mitigation potential. Compared with the bottom-up type model, in top-down integrated assessment models such as AIM/Computable General Equilibrium (AIM/CGE), which has been widely used for climate change mitigation and impact assessment [22-28], travel demand is dynamically estimated with relative prices and the elasticity of substitution. However, AIM/CGE represents transport at a highly aggregated level, but technological details and behavioral determinants such as travel cost, travel time, modal split, and preference are not incorporated. This implies that current models cannot be applied to investigate global transport dynamics and the mitigation potential of transport technological and behavioral options. 
The choice of transport mode for a personal trip is determined by various attributes, such as travel cost, travel time, personal preference, and individual socioeconomic characteristics. This determines travel behavior and can affect the travel demand and transport-related GHG emissions [29-31]. Thus, a transport mode decision model provides a methodology to estimate the travel demand and modal split, and is commonly applied to transport planning and policy analysis. Several studies have used a discrete choice model to analyze an individual's travel behavior based on choices made regarding the mode, technology, and individual attributes [32-36]. In a transport mode decision model, the traveler's utility associated with alternative travel modes is modeled by computing variables that describe the features of different travel modes and a traveler's preference among them. Transport mode decision models using multinomial logit type equations have been linked with integrated assessment models such as Targets IMage Energy Regional (TIMER), Global Change Assessment Model (GCAM), The Integrated MARKAL-EFOM System (TIMES), Model for Energy Supply Strategy Alternatives and their General Environmental Impact (MESSAGE), General Equilibrium Model for Economy - Energy - Environment (GEM-E3), and IMACLIM-R. to estimate the travel demand and modal share for climate mitigation analysis from the perspectives of transport policy and behavior [37-45]. The MESSAGE-Transport model creates a triangular arrangement of three soft-linked models to incorporate transport mode choices and individual vehicle technologies into the partial-equilibrium model MESSAGE. A larger-scale economic-engineering model for passenger and freight transport PRIMES-TREMOVE was linked with the GEM-E3T, which has been enhanced based on the standard GEM-E3 for modeling the transport sector [44]. The IMACLIM-R model offers a detailed representation of passenger and freight transportation for the energy-economy-environment (E3) IAM, taking into account the deployment of transport infrastructure. It was found that the GDP loss with a fixed carbon emission trajectory can be reduced by the deployment of infrastructure for roads and air travel [46]. It is difficult to deal with the interactive impacts of transport policy interventions on the macro-economy because the dynamic feedback or interplay between the transport sector and CGE models are seldom taken into consideration.

To improve the transport sector representation in CGE models, this study developed a global passenger transport model, AIM/Transport, which was coupled with AIM/CGE. AIM/Transport can provide an elaborate technological description of the transport sector and evaluate the technological feasibility of transport policies, whereas individual transport models are not able to investigate the interaction between the transport sector and the macro-economy, and the response of other sectors to transport policy interventions. Coupling with AIM/CGE overcomes this shortcoming of AIM/Transport because the CGE model covers all goods and service transactions; thus, an interactive analysis of the transport sector and other sectors becomes possible. The transport representation in AIM/CGE is also enriched because the 
CGE model uses either a production function or price elasticity to represent the aggregated transport sector and, therefore, lacks an explicit transport representation, including mode and technological details.

In this context, this study of the use of AIM/Transport, which has a detailed representation of transport technologies and is coupled with the CGE model, had three objectives: (1) to demonstrate how to couple a transport model within a CGE model; (2) to provide detailed transport representation for a global CGE model; and (3) to create a better understanding of the interactive mechanism between the transport sector and macro-economic system.

The paper is organized as follows. Section 2 describes the model structure, iterative algorithm, formulations, data source, and scenario settings. Section 3 presents the model integration and convergence of coupling for the CGE-Transport model and how the feedback of AIM/Transport updates the transport representation in AIM/CGE, followed by an analysis of results for the $\mathrm{BaU}$ and mitigation scenarios. Section 4 provides a discussion of the interpretation and the implications of the simulation results. Section 5 is a conclusion that summarizes the findings, with a roadmap for future research tasks.

\section{Methodology}

\subsection{Model interaction}

In this study, a global passenger transport model, AIM/Transport, was developed to analyze the transport sector representation by incorporating travelers' modes of choice and technological details, and then estimating the resulting energy consumption and GHG emissions. AIM/Transport was coupled with AIM/CGE to capture interactive mechanisms between the transport sector, energy consumption, GHG emissions, and the macroeconomic system. AIM/CGE is a one-year interval recursive-type, dynamic, general equilibrium model that covers all regions of the world. This CGE model consists of 17 regions and 42 industrial classifications. Details of the model structure and mathematical formulas are provided in the AIM/CGE manual [47].

To integrate AIM/CGE and AIM/Transport, an iterative procedure was used to obtain the convergence between AIM/Transport and AIM/CGE. As shown in Figure 1, if the energy consumption calculated in AIM/Transport differs from that consumed by the transport sector in AIM/CGE, the travel demand, energy consumption, and capital cost from the transport model is fed back into AIM/CGE to re-estimate the related parameters of the transport sector in AIM/CGE. AIM/CGE then passes the updated energy prices and carbon prices to AIM/Transport. This loop continues until the energy consumed in AIM/CGE and AIM/Transport reaches a convergence. 


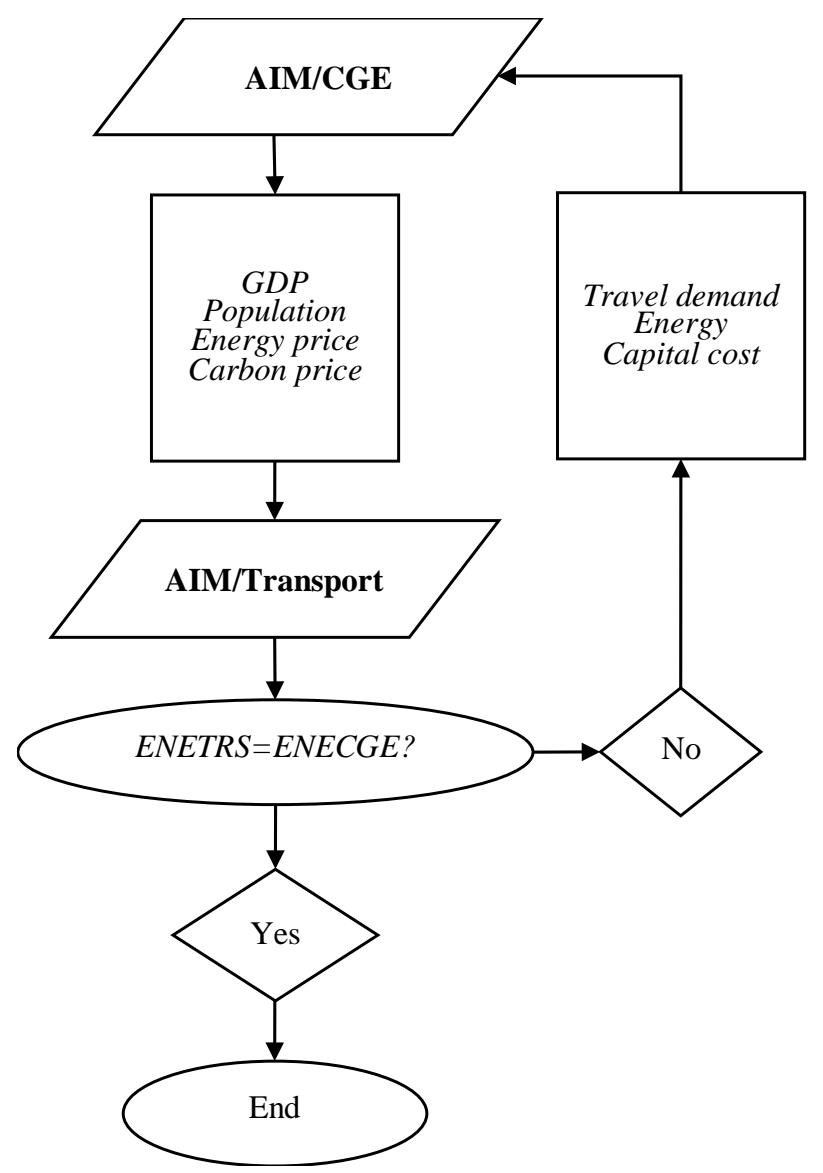

Figure 1. Iterative algorithm of the coupled Asia-Pacific Integrated Model /Computable General Equilibrium (AIM/CGE) and AIM/Transport

(ENETRS and ENECGE are energy consumption in AIM/Transport and AIM/CGE, respectively)

\subsection{AIM/Transport}

\subsubsection{Overview}

AIM/Transport for global passenger travel simulation was developed for 17 regions, which is consistent with AIM/CGE (Figure S1 and Table S1 in Supporting Information). Figure 2 shows the overall framework of AIM/Transport. The passenger travel demand for each region is computed based on GDP, population, and generalized transport cost, which is calculated from the outcomes of the energy and carbon price determined from AIM/CGE, and travel time cost estimated from the wage rate and vehicle velocity. The total travel demand is divided into different distances, modes, vehicle sizes, and technologies by mode choice models using multinomial logit equations based on the generalized transport cost of each category. The energy consumed by passenger trips in each region can be evaluated according 
to the travel demands of each technology category and technology-wise energy intensities. GHG emissions produced by the transport sector can be assessed according to the energy consumption and emission intensity coefficient for each fuel.

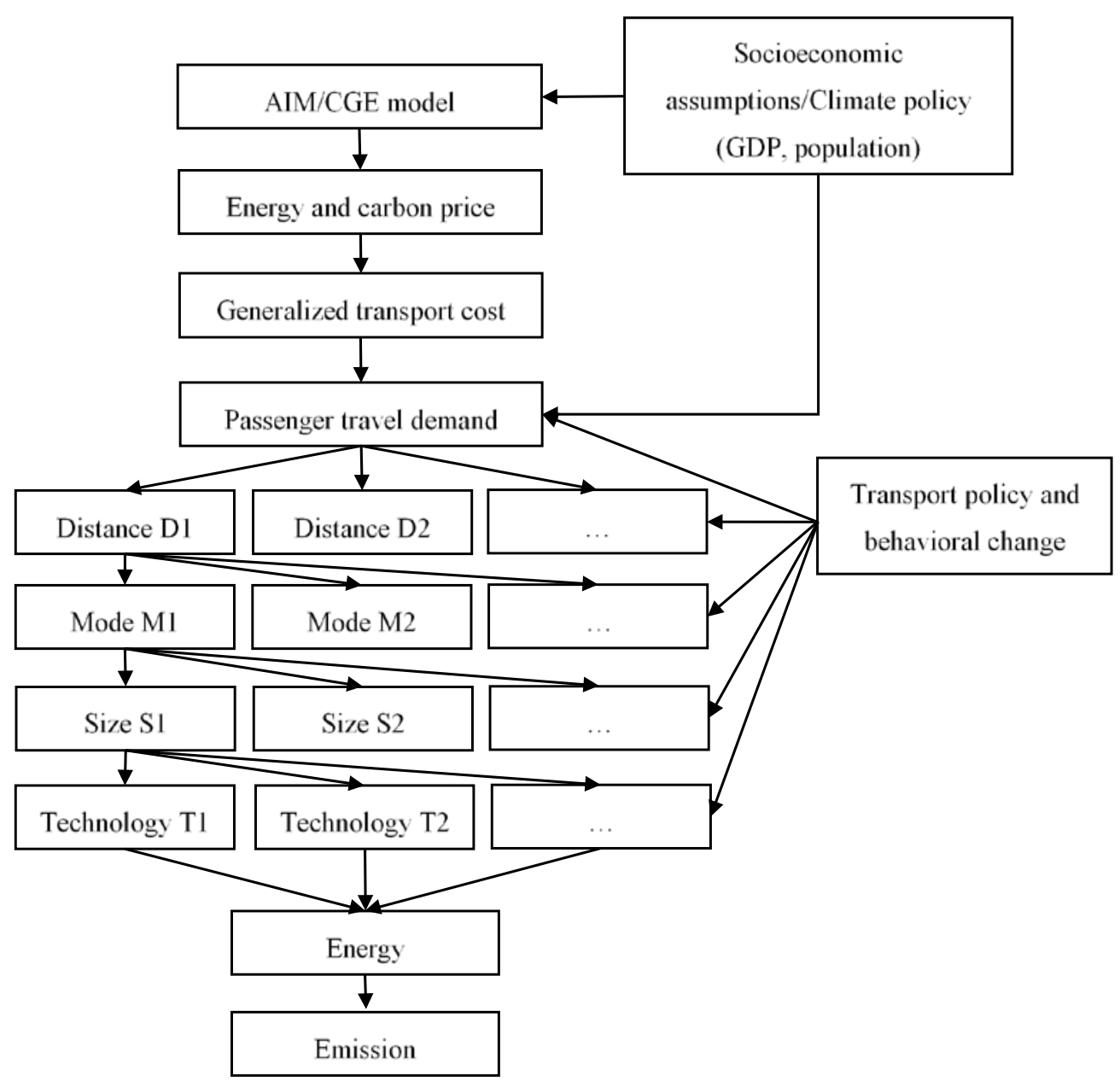

Figure 2. The structure of Asia-Pacific Integrated Model/Transport (AIM/Transport)

\subsubsection{Formulations}

The following equation (1) is used to calculate the total transport volume. The travel demand is estimated as a function of GDP per capita, population, and generalized travel cost.

$$
Q_{r, y}=a_{r} \times\left(\frac{g d p_{r, y}}{p o p_{r, y}}\right)^{\alpha_{r}} \times P_{r, y} \beta_{r} \times p o p_{r, y}
$$

where $Q_{r, y}$ is the total transport volume in region $r$ and year $y$, respectively; gdp $\mathrm{p}_{\mathrm{r}, y}$ and $p_{\mathrm{p}} \mathrm{p}_{r, y}$ are the gross domestic product (US 2005 constant) and population in region $r$ and year $y$, respectively; $P_{r, y}$ is the 
generalized travel cost in region $r$ and year $y$, respectively; and $a_{r}, \alpha_{r}$, and $\beta_{r}$ are parameters estimated based on the baseline data.

Because the total transport flow is divided into long distance and short distance travel, the generalized travel cost $P_{r, y}$ equals the weighted sum of the distance-wise price $P D I S_{r, y, d}$.

$$
P_{r, y}=\sum_{d \in D} S D I S_{r, y, d} \times P D I S_{r, y, d}
$$

where $S D I S_{r, y, d}$ is the share of each distance $d$, which can be calculated using a multinomial logit equation based on the generalized distance-wise price $P D I S_{r, y, d}$. Let $d \in D$ be the set of distance specific alternatives, and $\alpha^{\text {dis }}$ and $\beta^{\text {dis }}$ be the alternative-specific coefficient and price coefficient, respectively. The equations for calculating $S D I S_{r, y, d}$ and distance-wise travel volume $Q D I S_{r, y, d}$ are then:

$$
\begin{gathered}
S D I S_{r, y, d}=\frac{\alpha_{r, d}^{d i s} \times P D I s_{r, y, d}^{\beta_{r, d}^{d i s}}}{\sum_{d \in D}\left(\alpha_{r, d}^{d i s} \times P D I S_{r, y, d}^{\beta_{r, d}}\right)} \\
Q D I S_{r, y, d}=Q_{r, y} \times S D I S_{r, y, d}
\end{gathered}
$$

Similarly, the distance-wise transport volume can be further divided into different modes including car, bus, two wheelers, domestic aviation, international aviation, and railway; thus, the distance-wise price $P D I S_{r, y, d}$, mode share $S M O D E_{r, y, d, m}$, and transport volume for each model $Q M O D E_{r, y, d, m}$ were computed as equations (5), (6), and (7).

$$
\begin{aligned}
& P D I S_{r, y, d}=\sum_{m \in M} S M O D E_{r, y, d, m} \times P M O D E_{r, y, d, m}
\end{aligned}
$$

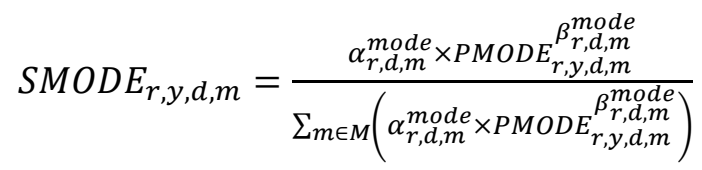

$$
\begin{aligned}
& Q M O D E_{r, y, d, m}=Q D I S_{r, y, d} \times S M O D E_{r, y, d, m}
\end{aligned}
$$

It is assumed that the travel time is considered only at the transport mode level, but the vehicle size and technology levels do not take into account the differences in travel time. Transport mode choice is determined not only by financial cost but also the monetary cost of travel time, indicating that travelers prefer cheap, rapid, convenient, and efficient transport modes for person trips. The same structure of mode choice model is often used for the modal split of the classical transportation four-step model (FSM) [48]. Thus, the price of each mode $P M O D E_{r, y, d, m}$ is equal to the generalized cost of technology within each vehicle size category plus the monetary cost of travel time ptime $e_{r, y, d, m}$. As shown in equation (9), the 
monetary cost of travel time for each mode $m$ can be estimated by dividing the wage rate by the door-to-door speed $d d t s_{r, y, d, m}$. In this study, we used GDP per capita divided by annual working time $a w h_{r, y}$ as a proxy for wage rate due to data limitations. This implies that travelers tend to shift towards faster travel modes to reduce the monetary cost of travel time. At the next level, another multinomial logit equation is used to calculate the share of different vehicle sizes $S S I Z E_{r, y, d, m, s}$, i.e., small, medium, and large, and size-wise price PSIZE $E_{r, y, d, m, s}$ and transport volume $Q S I Z E_{r, y, d, m, s}$ are also exhibited in equations (11) and (12).

$$
\begin{aligned}
& P M O D E_{r, y, d, m}=\sum_{s \in S} S S I Z E_{r, y, d, m, s} \times P S I Z E_{r, y, d, m, s}+p t i m e_{r, y, d, m} \\
& \text { ptime }_{r, y, d, m}=\frac{g d p_{r, y}}{\text { pop }_{r, y} \times a w h_{r, y} \times d d t s_{r, y, d, m}} \\
& S S I Z E_{r, y, d, m, s}=\frac{\alpha_{r, d, m, s}^{s i z e} \times P S I Z E_{r, y, d, m, s}^{\beta_{r, s}^{s i z e}}}{\beta_{s \in S}^{s i z}\left(\alpha_{r, d, m, s}^{s i z e} \times P S I Z E_{r, y, d, m, s}^{\beta_{r, d, s}}\right)} \\
& \operatorname{PSIZE}_{r, y, d, m, s}=\sum_{t \in T} S T E C_{r, y, d, m, s, t} \times P T E C_{r, y, d, m, s, t} \\
& Q S I Z E_{r, y, d, m, s}=Q M O D E_{r, y, d, m} \times S S I Z E_{r, y, d, m, s}
\end{aligned}
$$

The travel cost of each technology $P T E C_{r, y, d, m, s, t}$ consists of the price of fuel $p f u e l_{r, y, d, m, s, t, f}$, carbon tax $p g g_{r, y, d, m, s, t, f}$, and the annualized purchase cost for the device pdevice $e_{r, y, d, m, s, t}$. Then the transport demand of technology $t, Q T E C_{r, y, d, m, s, t}$, is the sum of the demand for the technology $t$ in the previous year QTEC $C_{r, y-1, d, m, s, t}$ multiplied by one minus the depletion rate $\tau$ and the demand for new technology investment in year $y, Q T E C N E W_{r, y, d, m, s, t}$, and then multiplied by the operation rate $O P R_{r, y, d, m, s}$. The QTECNEW $W_{r, y, d, m, s, t}$ can be calculated based on the price of technology using multinomial logit equations and the total new investment $Q T E C N E W T_{r, y, d, m, s}$ as shown in equation (15). Then, the market share of technology $t$ STEC $C_{r, y, d, m, s, t}$ equals the transport demand of technology $t$ divided by the transport demand for vehicle size $s$. To close this system of equations, the size-wise transport demand $Q S I Z E_{r, y, d, m, s}$ is also equal to the sum of $Q T E C_{r, y, d, m, s, t}$. Energy consumption $E N E_{r, y, d, m, s, t, f}$ for region $r$, year $y$, distance $d$, mode $m$, size $s$, technology $t$, and fuel $f$, is the sum of the travel demand $q$ tecpre $e_{r, y, d, m, s, t}$ and $Q T E C N E W_{r, y, d, m, s, t}$ multiplied by the energy intensity eipre $e_{r, y, d, m, s, t, f}$ of the previous year and $e i_{r, y, d, m, s, t, f}$ of this year. Fuel price, carbon price, device price, and energy intensity are estimated from the results of AIM/CGE, the database of the AIM/Enduse model [18, 19], and the mode specific load factors [49].

$$
\operatorname{PTEC}_{r, y, d, m, s, t}=\sum_{f \in F}\left(\text { fuel }_{r, y, d, m, s, t, f}+\operatorname{pghg}_{r, y, d, m, s, t, f}\right)+\text { pdevice }_{r, y, d, m, s, t}
$$




$$
\begin{aligned}
& Q T E C_{r, y, d, m, s, t}=\left[\text { qtecpre }_{r, y, d, m, s, t} \times\left(1-\tau_{r, y, d, m, s, t}\right)+Q T E C N E W_{r, y, d, m, s, t}\right] \times O P R_{r, y, d, m, s} \\
& Q T E C N E W_{r, y, d, m, s, t}=\frac{\alpha_{r, d, m, s, t}^{t e c} \times P T E C_{r, y, d, m, s, t}^{\beta_{r, d}^{t e c}}}{\sum_{t \in T}\left(\alpha_{r, d, m, s, t}^{t e c} \times P T E C_{r, y, d, m, s, t}^{\beta_{r, d, m, t}}\right)} \times Q T E C N E W T_{r, y, d, m, s} \\
& S T E C_{r, y, d, m, s, t}=\frac{Q T E C_{r, y, d, m, s, t}}{Q S I Z E_{r, y, d, m, s}} \\
& Q S I Z E_{r, y, d, m, s}=\sum_{t \in T} Q T E C_{r, y, d, m, s, t} \\
& E N E_{r, y, d, m, s, t, f}=q t e c p r e_{r, y, d, m, s, t} \times\left(1-\tau_{r, y, d, m, s, t}\right) \times e i p r e_{r, y, d, m, s, t, f}+Q T E C N E W_{r, y, d, m, s, t} \times \\
& \quad e i_{r, y, d, m, s, t, f} \\
& O P R_{r, y, d, m, s} \geq 0
\end{aligned}
$$

The variables of AIM/Transport are endogenously determined by each other; i.e., AIM/Transport expressed as equations (1) - (19) is a system of nonlinear equations that cannot be solved analytically. In equation (19), $O P R_{r, y, d, m, s}$ and $Q T E C N E W T_{r, y, d, m, s}$ are greater than or equal to zero because the Mixed Complementarity Problem (MCP) is used in the mathematical programming to solve this system of equations. Thus, we rely on a numerical computation based on the General Algebraic Modelling System (GAMS) to obtain the equilibrium solutions. The model variables are summarized in Table S2 in the Supporting Information. The endogenous and exogenous variables are represented as upper and lower case, respectively. Moreover, the convergence of AIM/CGE and AIM/Transport can be obtained using the iterative algorithm displayed in Figure 1. $E N E T R S_{r, y, f}$ and $E N E C G E_{r, y, f}$ are energy consumption for fuel $f$ in region $r$ and year $y$ in AIM/Transport and AIM/CGE, respectively. If the ENETRS $S_{r, y, f}$ is not equal to $E N E C G E_{r, y, f}, \mathrm{AIM} / \mathrm{CGE}$ will be run again with the re-estimated parameters based on the $Q M O D E_{r, y, d, m}$,

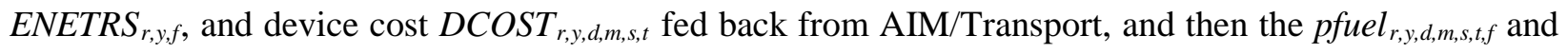
$\operatorname{pghg}_{r, y, d, m, s, t, f}$ from AIM/CGE are updated. Such iterative computations will be performed until the $E E T R S_{r, y, f}$ is equal to $E N E C G E_{r, y, f}$ or the differences between them are less than the iteration convergence tolerance value. The energy consumption and capital cost fed back from AIM/Transport to AIM/CGE can be computed as equations (19) and (20):

$$
\begin{aligned}
& \operatorname{ENETRS}_{r, y, f}=\sum_{d \in D, m \in M, s \in S, t \in T} \operatorname{ENE}_{r, y, d, m, s, t, f} \\
& \operatorname{DCOST}_{r, y, d, m, s, t}=\operatorname{QTEC}_{r, y, d, m, s, t} \times \text { pdevice }_{r, y, d, m, s, t}
\end{aligned}
$$

\subsection{Analytical method for model integration}


To judge whether and how the model integration can achieve the convergence, discrepancies between the simulation results of AIM/CGE and AIM/Transport were calculated. The Mean Absolute Percentage Error (MAPE) was used as the discrepancy indicator to detect the discrepancies, and these were calculated by the following equation [50]:

$$
M A P E_{r, f}=\sum_{y \in Y} \frac{1}{n}\left|\frac{\operatorname{ENETRS}_{r, y, f}-E N E C G E_{r, y, f}}{E N E C G E_{r, y, f}}\right|
$$

where $M A P E_{r, f}$ is the Mean Absolute Percentage Error of fuel $f$ in region $r$ and $n$ represents the number of years. We set the regional mean MAPE as the convergence criterion, with a value set to $1 \%$. When the regional mean $M A P E$ for each fuel type is less than $1 \%$, the iteration stops.

Additionally, the bias in the discrepancies between AIM/CGE and AIM/Transport should be investigated to identify the regions and years in which there were large discrepancies for each type of fuel. The following regression method was used to systematically detect the bias in the discrepancies [50]:

$$
\left|L N \frac{E^{E N T R R} S_{r, y, f}}{\operatorname{ENECGE}_{r, y, f}}\right|=L N a_{f, r}+L N b_{f, y}+L N c_{f}+\varepsilon_{r, y, f}
$$

where $a_{f, r}, b_{f, y}$, and $c_{f}$ are regressed parameters and $\varepsilon_{r, y, f}$ is the residual. $a_{f, r}$ and $b_{f, y}$ indicate the bias of the discrepancy in regions and years, respectively.

\subsection{Data}

Data for the parameter estimation, calibration, and simulation of AIM/Transport were collected for 17 regions (Table 1). Socioeconomic data, such as GDP and population, were obtained from the shared socioeconomic database [51]. Shared Socioeconomic Pathways 2 (SSP2) estimates were used as default values for the GDP and population in the transport model, and were characterized as 'middle of the road' among a range of scenarios. The travel demand for distances, modes, vehicle sizes, technologies, energy consumption, and energy intensity were simultaneously reconciled to ensure that the reconciled and observed data were as similar to each other as possible. The vehicle device cost, technology-wise energy intensity, and annual distance travelled were derived from AIM/Enduse [18, 19]. The load factor and door-to-door speed for the travel time calculation were taken from GCAM [49]. Parameters $A$, $\alpha$, and $\beta$ for the total travel demand and all levels including distances, modes, sizes, and technologies were calibrated based on the base year data in 2005. The target periods of both AIM/CGE and AIM/Transport in this study were 2005-2100, with one-year intervals.

Table 1. Data sources for Asia-pacific Integrated Model/Transport (AIM/Transport) 


\begin{tabular}{cccc}
\hline Data & Description & Source & Reference \\
\hline GDP & Region specific & SSP database & {$[51]$} \\
Population & Region specific & SSP database & {$[51]$} \\
Vehicle device cost & Mode and technology specific & AIM/Enduse model & {$[18,19]$} \\
Energy intensity & Mode and technology specific & AIM/Enduse model & {$[18,19]$} \\
Annual distance travelled & Region and mode specific & AIM/Enduse model & {$[18,19]$} \\
Load factor & Region and mode specific & GCAM model & {$[49]$} \\
Door-to-door speed & Mode specific & GCAM model & {$[49]$} \\
\hline
\end{tabular}

\subsection{Scenario setting}

One of the main objectives of this study was to develop a methodological framework for an integrated CGE and transport model. Thus, to test the feasibility of coupling a CGE-Transport model, a BaU scenario was prepared to identify whether the model integration could achieve a convergence. In the BaU scenario, the GDP and population were aligned with the SSP2 scenario. It was assumed that car ownership and usage will increase over the coming decades in line with the increases in GDP in developing regions, implying that the average vehicle occupancy decreases accordingly. The coefficient of the logit model for mode level $\alpha^{\text {mode }}$ represents the travelers' preference toward a specific travel mode and this coefficient for developing countries will converge to the values of developed countries in future years. Assuming that the United States and Japan are typical examples of a car-oriented and public-transit oriented society, respectively, the average mode preference coefficients of the United States and Japan in 2005 were taken as the target values in 2100 for developing regions. A mitigation scenario was considered that corresponded to a two-degree climate stabilization target to test the robustness of model integration and to determine whether the mitigation cost can be changed by the model integration (named carbon tax scenario). The carbon price was set at a level designed to achieve a $450 \mathrm{ppm} \mathrm{CO}_{2}$ equivalent concentration $\left(2.7 \mathrm{~W} / \mathrm{m}^{2}\right)$ by 2100 , and this carbon price pathway was calculated by AIM/CGE.

\section{Results}

\subsection{Model iteration and convergence}

AIM/CGE and AIM/Transport yielded different results for transport-related energy consumption without model integration. Figure 3(a) shows the differences in transport-related energy consumption between the two models. The consumption of coal and oil calculated by AIM/Transport was lower than that consumed by the transport sector in AIM/CGE, while the quantities of electricity and gas consumed in 
AIM/Transport were higher than in AIM/CGE. To integrate the merits of both AIM/CGE and AIM/Transport, the numerical computation was coupled using the iterative algorithm shown in Figure 2. Table 2 and Figure 4 show the discrepancies for each iteration to compare the fuel-wise and region-wise energy consumption between AIM/CGE and AIM/Transport using MAPE. The MAPE of all five fuels decreased with more iterations and was less than $1 \%$ after thirteen iterations, implying the model integration achieved a convergence (Table 2). The convergence was also proved by the declining trends of region-wise MAPE displayed in Figure 4. It was notable that biomass had a relatively high discrepancy and slow convergence rate compared with other fuels. The reason for this might be that the energy intensity coefficients for biomass in AIM/Transport are estimated by the energy intensity coefficients for oil and the ratios between oil and biomass and, therefore, the indirect parameter that passes through the iterations generates a relatively slower convergence speed. After the convergence of coupling was achieved, the energy consumed by the transport sector in AIM/CGE approximates to the estimates of AIM/Transport. As displayed in Figure 3(b), the trajectories for five fuels projected by AIM/CGE were almost overlapped by those estimated by AIM/Transport after thirteen iterations.

(a)

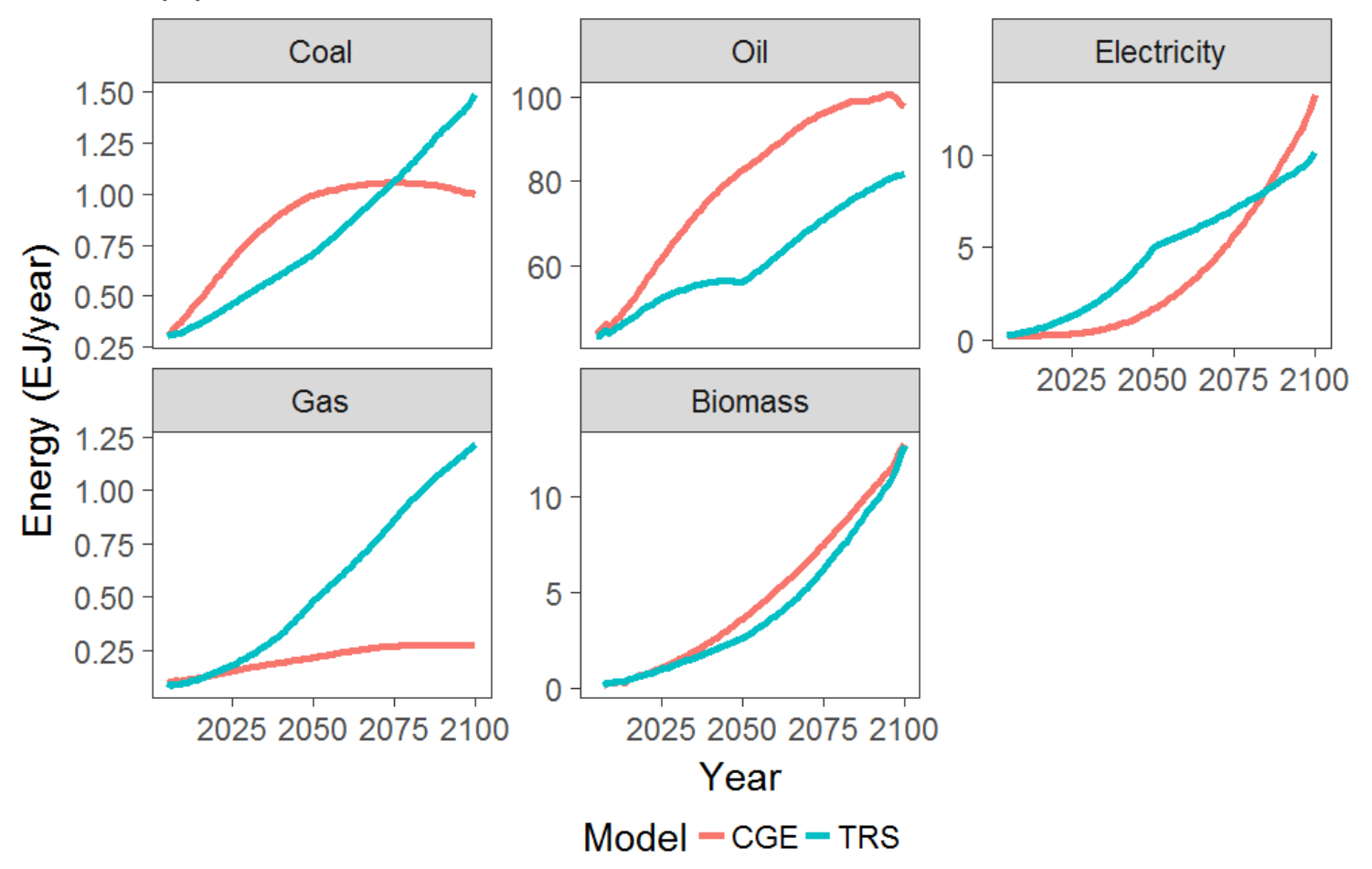


(b)

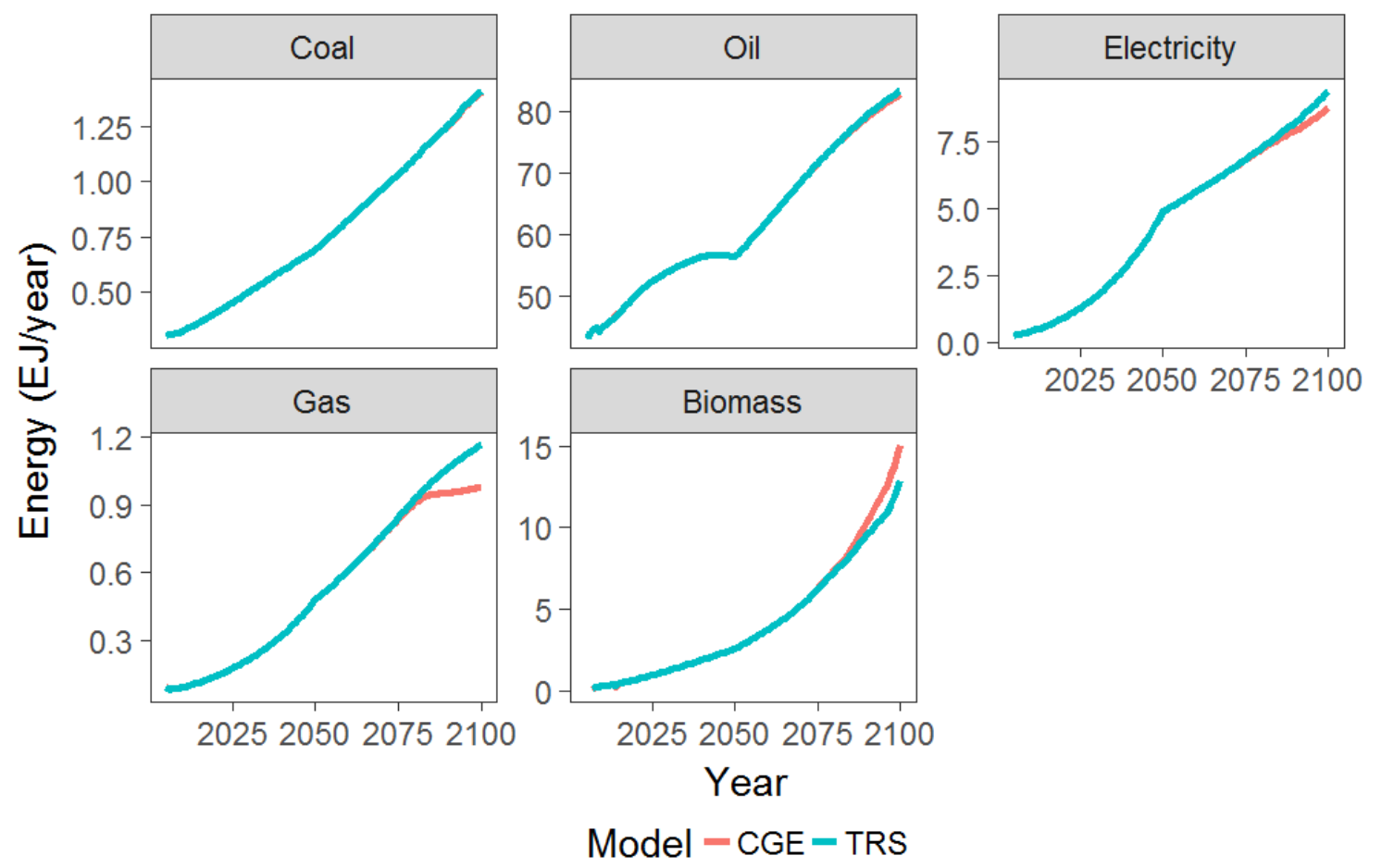

Figure 3. Transport-related energy consumption in Asia-pacific Integrated Model /Computable General Equilibrium (AIM/CGE) and AIM/Transport before (a) and after (b) coupling

Table 2. Regional mean fuel-wise Mean Absolute Percentage Error (MAPE) (\%) of the business as usual (BaU) scenario

\begin{tabular}{cccccc}
\hline Iteration & Coal & Oil & Electricity & Gas & Biomass \\
\hline 1 & 12.79 & 2.35 & 3.69 & 2.55 & 15.12 \\
2 & 0.80 & 0.62 & 3.12 & 3.01 & 15.05 \\
3 & 0.62 & 0.66 & 3.14 & 3.63 & 4.99 \\
4 & 0.50 & 0.39 & 2.06 & 2.33 & 6.84 \\
5 & 0.30 & 0.46 & 2.13 & 2.61 & 3.18 \\
6 & 0.26 & 0.24 & 1.27 & 1.51 & 4.34 \\
7 & 0.12 & 0.32 & 1.44 & 1.85 & 2.08 \\
8 & 0.10 & 0.14 & 0.75 & 0.94 & 3.07 \\
9 & 0.05 & 0.22 & 0.97 & 1.34 & 1.43 \\
10 & 0.03 & 0.07 & 0.45 & 0.61 & 2.45 \\
11 & 0.02 & 0.15 & 0.65 & 0.96 & 1.11 \\
12 & 0.01 & 0.05 & 0.29 & 0.42 & 1.87 \\
13 & 0.01 & 0.09 & 0.40 & 0.63 & 0.91 \\
\hline
\end{tabular}



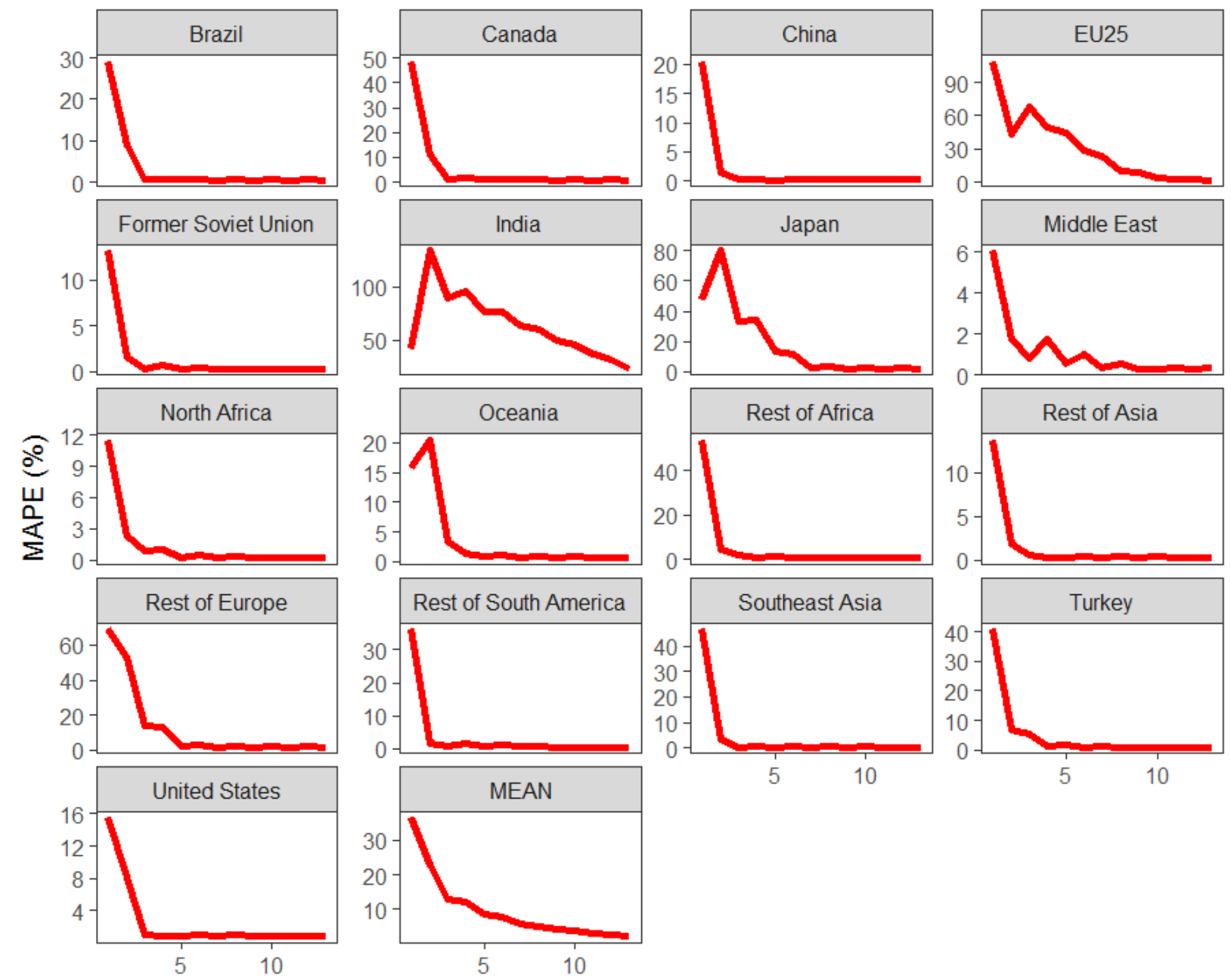

Iteration

Figure 4. Region-wise Mean Absolute Percentage Error (MAPE) (\%) of the business as usual (BaU) scenario

The MAPE demonstrated that the iterative model integration could converge to a stable state where the transport sector in AIM/CGE consumes the same amount of energy as AIM/Transport. We further analyzed the bias in the discrepancies between AIM/CGE and AIM/Transport by regions and years to identify which regions and years for each fuel had a large discrepancy. As shown in Table 3 and Figure 5, the estimated parameters $a$ and $b$ represent the regional and time discrepancy bias. Table 3 shows that oil and coal had relatively flat values, but electricity, gas, and biomass had high values in India. This was due to the large discrepancies between AIM/CGE and AIM/Transport in India. The discrepancies of electricity and gas in India before the model integration were much higher than in other regions. Due to the large original differences before the iterative model coupling, the MAPE in Figure 4 still shows a high value in India after thirteen iterations. Although Canada, EU25, Japan, and the rest of Europe also had 
high discrepancies in the initial iterations, the convergence in those regions performed much better than did that of India, because the discrepancies shown in Figure 4 are MAPE considering all years from 2005 to 2100. The calibration and parameter adjustments between AIM/Transport and AIM/CGE were based on mainly the energy consumption in the base year 2005. India had the greatest discrepancy between AIM/Transport and AIM/CGE before coupling in 2005; therefore, the convergence speeds in India were slower than those were in other regions. Figure 5 shows that the discrepancies of electricity, gas, and biomass tended to increase with an increase in the number of years. This is consistent with the MAPE in Table 2, which shows higher values for electricity, gas, and biomass than other fuels. The reason for this was also the greater original discrepancies of these fuels before model integration.

The BaU scenario simulation demonstrated that the model integration of AIM/CGE and AIM/Transport could achieve convergence. It was necessary to further conduct a mitigation scenario simulation to identify whether the model integration was robust for other scenarios. Simulation results showed that the discrepancies of the mitigation scenario, where a carbon tax was imposed, could also decrease to less than $1 \%$ after five iterations. A convergence of model integration between AIM/CGE and AIM/Transport was also reached, indicating the robustness of the model for other scenarios.

Table 3. Estimated parameter $a$ in the regression results

\begin{tabular}{|c|c|c|c|c|c|}
\hline Region & Coal & Oil & Electricity & Gas & Biomass \\
\hline Rest of Africa & 1.0003 & 0.9993 & 0.9950 & 1.0000 & 0.9925 \\
\hline North Africa & 1.0000 & 0.9992 & 0.9950 & 0.9907 & 0.9919 \\
\hline Oceania & 1.0000 & 0.9993 & 0.9953 & 0.9908 & 0.9925 \\
\hline Canada & 0.9998 & 0.9993 & 0.9950 & 1.0000 & 0.9924 \\
\hline China & 0.9999 & 0.9992 & 0.9949 & 0.9908 & 0.9921 \\
\hline Rest of Europe & 1.0000 & 0.9993 & 0.9955 & 0.9916 & 0.9929 \\
\hline Turkey & 0.9998 & 0.9996 & 0.9952 & 1.0000 & 0.9923 \\
\hline $\begin{array}{c}\text { Former Soviet } \\
\text { Union }\end{array}$ & 1.0000 & 0.9992 & 0.9951 & 0.9908 & 0.9921 \\
\hline India & 1.0005 & 1.0115 & 1.0634 & 1.0894 & 1.0953 \\
\hline Japan & 1.0000 & 0.9994 & 0.9951 & 0.9909 & 0.9934 \\
\hline Brazil & 0.9998 & 0.9991 & 0.9950 & 0.9908 & 0.9921 \\
\hline $\begin{array}{c}\text { Rest of South } \\
\text { America }\end{array}$ & 0.9998 & 0.9990 & 0.9949 & 0.9908 & 0.9919 \\
\hline Middle East & 1.0000 & 0.9991 & 0.9950 & 0.9910 & 0.9922 \\
\hline Southeast Asia & 1.0000 & 0.9996 & 0.9951 & 0.9909 & 0.9924 \\
\hline Rest of Asia & 1.0000 & 0.9994 & 1.0000 & 0.9908 & 0.9923 \\
\hline
\end{tabular}


United States

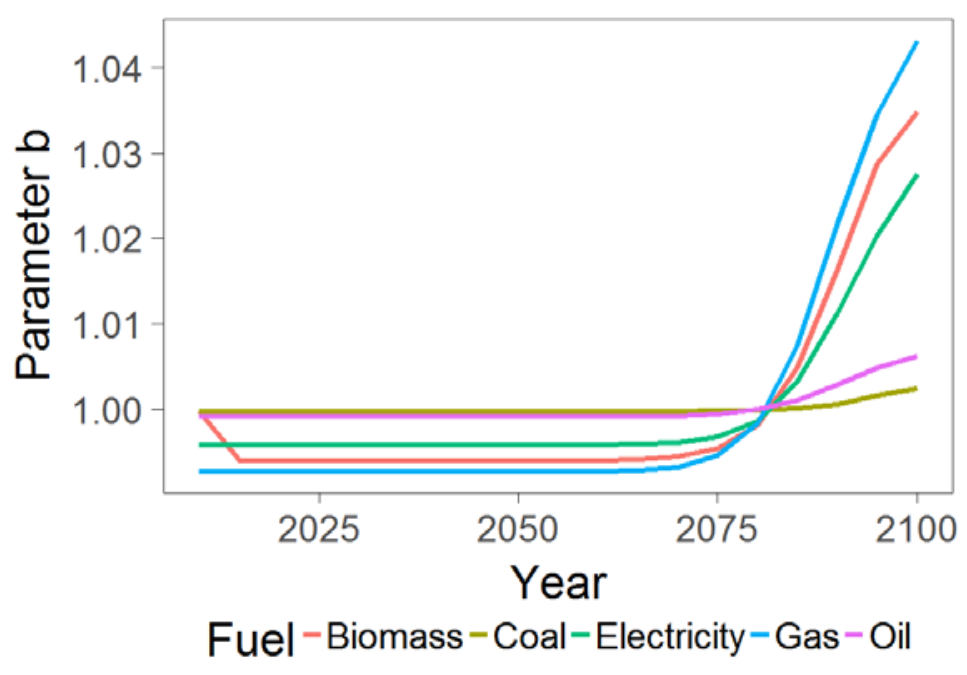

Figure 5. Estimated parameter $b$

\subsection{Updated transport representation with AIM/Transport}

The feedback from AIM/Transport improves the transport representation in AIM/CGE. The global passenger travel demand and transport-related energy consumption in the CGE model were modified with the updated parameters estimated based on the feedback from AIM/Transport. Figure 6 shows that the travel demands for car, railway, and domestic aviation increased with model integration, while international aviation decreased after 2050. The travel demand for buses simulated with model integration was higher than the original value in AIM/CGE, but was lower after 2075. Because the transport-related energy uses in AIM/CGE after the iterative computation (shown in Figure 3(b)) were approximately the same as the values calculated in AIM/Transport, it was proven that the energy projections can also be updated by the feedback from AIM/Transport.

AIM/CGE and AIM/Transport have different internal model structures and driving mechanisms for simulating transport-related energy consumption in the future. In AIM/CGE, the energy consumption is formulated under the Linear Expenditure System (LES) function and the travel volume is simply formulated as a part of the industrial activity based on the elasticity of substitution and relative prices. Because the transport sector is represented at a highly aggregated level, with little technological detail, 
and includes factors such as travel time and mode preference, the structural shift in distances, modes, vehicle sizes, and technologies is not endogenously determined in the current transport representation. AIM/CGE fails to capture the changes in technological structure and mode preference, thereby resulting in an overestimation of conventional fossil fuels, such as oil. AIM/Transport is able to help mitigate the dependency of traditional energy sources in the transport sector estimated by AIM/CGE.
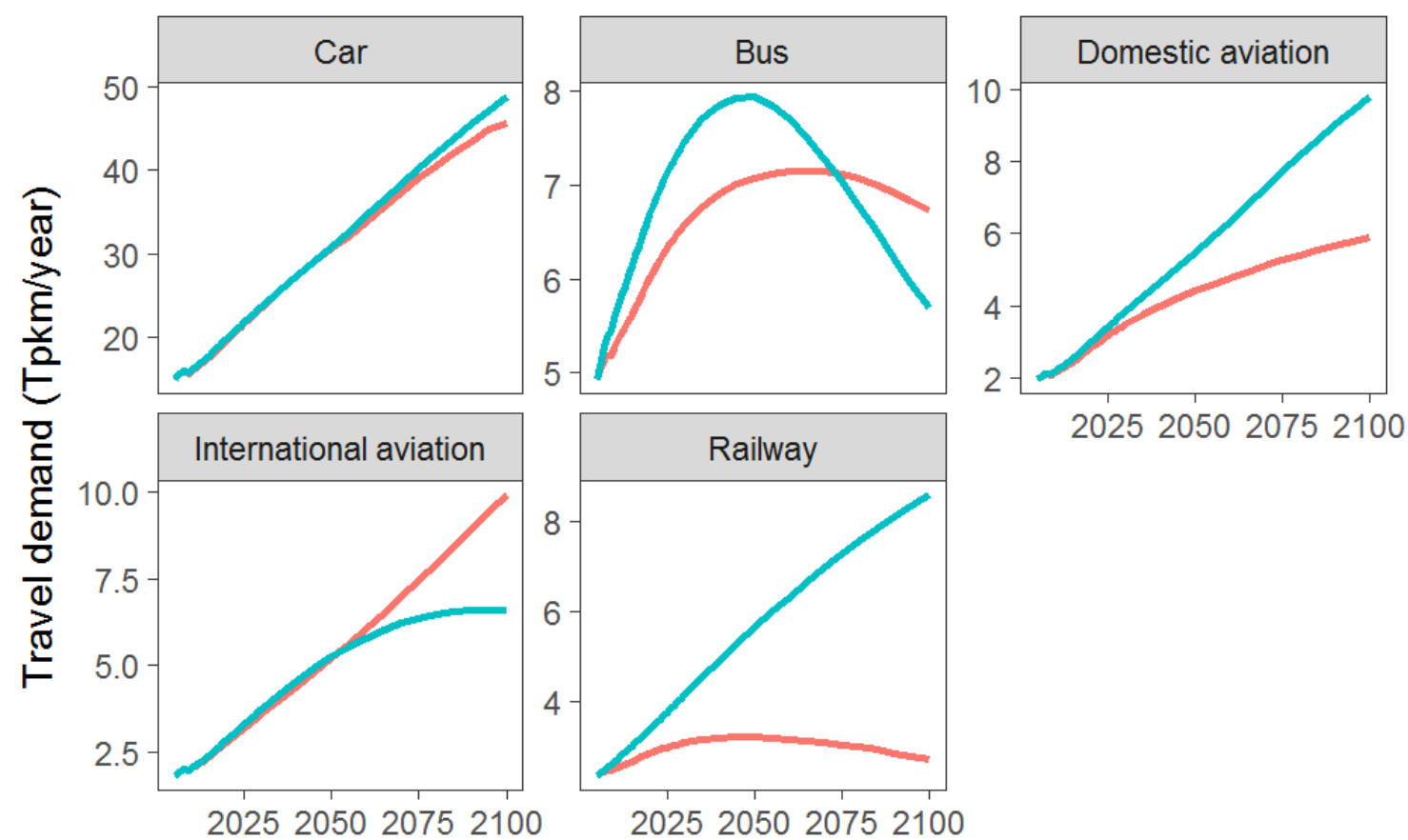

Figure 6. Travel demand in Asia-pacific Integrated Model /Computable General Equilibrium (AIM/CGE) with and without coupling with AIM/Transport

(Note: Car includes two wheelers in AIM/CGE)

\subsection{BaU scenario}

Figure 7(a) presents the global travel demand in the BaU scenario for 17 regions from 2005 to 2100. It is evident that the United States, European Union, India, China, Southeast Asia, and the rest of Africa account for large proportions of passenger travel demand in the world. Additionally, Figure 7(b) shows a negative correlation between GDP per capita in 2005 and annual growth rates from 2005 to 2100 in 17 regions. The annual growth rates of travel demand from 2005 to 2100 in developed countries and regions 
such as the United States, European Union, and Japan displayed stable tendencies, whereas developing regions such as India, Rest of Asia, and Rest of Africa constantly increased over the coming decades. The exception among the developing regions was China, where the passenger travel demand increased until the mid-21st century, but then gradually decreased. The reason for this might be that the population of China will witness a decline after the mid-21 $1^{\text {st }}$ century.

(a)

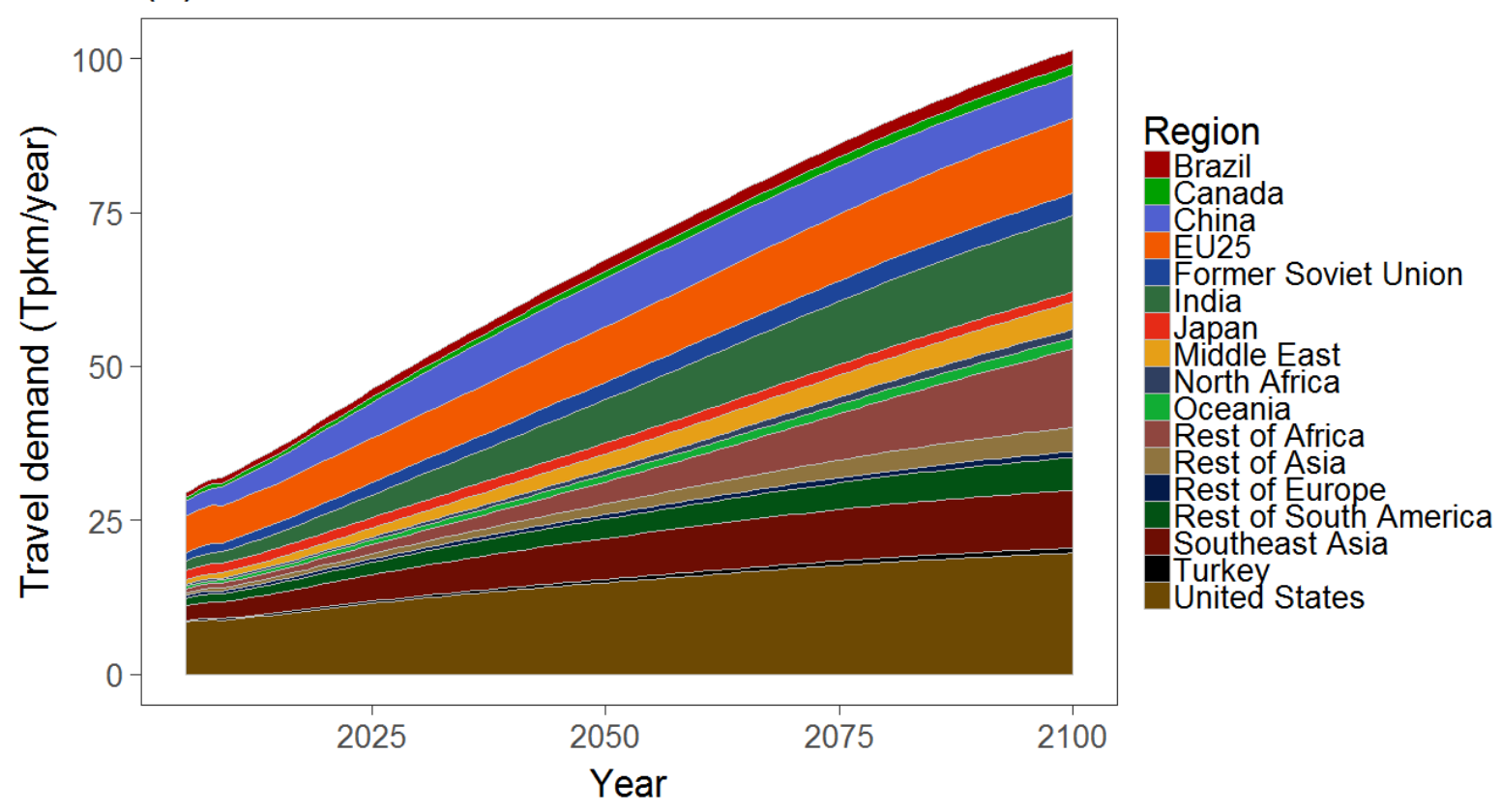

(b)

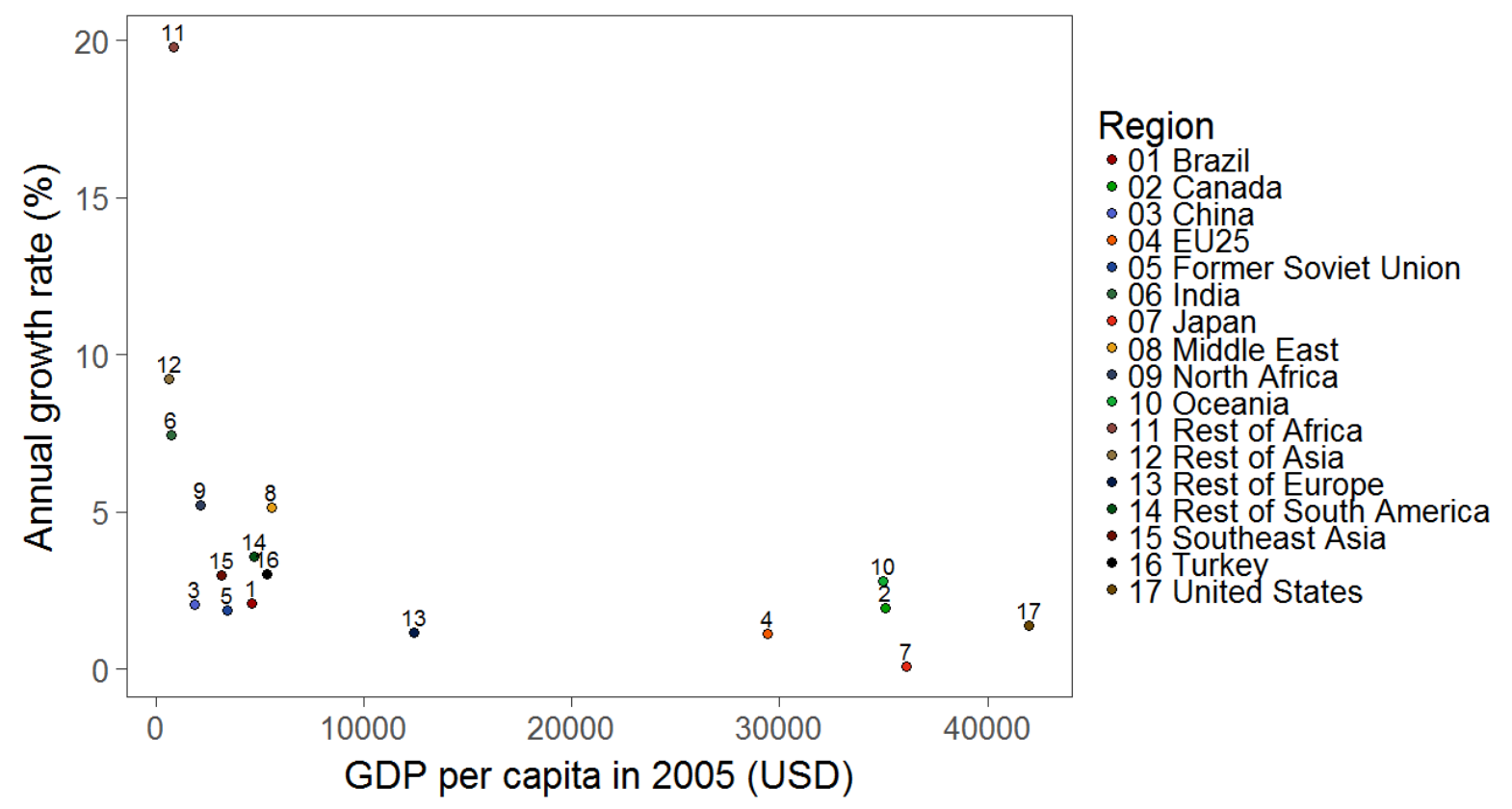




\section{Figure 7. Global travel demand (a) and growth (b) in 17 regions}

Figure 8 illustrates the modal split in 17 regions for car, bus, two wheelers, domestic aviation, international aviation, and railway transport. Changes in the share of passenger transport mode were characterized as a shift from mass transit modes (e.g., bus and railway) toward personalized modes (e.g., cars) on a global scale. As shown in Figure 8 (World), the share of car travel increased from 57.16\% in 2005 to $64.67 \%$ in 2100 , while the global share of bus travel decreased from $16.76 \%$ to $5.61 \%$. Similar to the different changing trends in travel demand in developing and developed regions, the modal split also displayed heterogeneity. The modal structures in developed regions such as the United States, Japan, the European Union, Canada, the Former Soviet Union, and Oceania were relatively stable, because car ownership in developed regions reached high levels in the 21st century. However, a significant structural shift from buses to cars occurred in developing regions like China, India, Brazil, Rest of Africa, Southeast Asia, and Rest of Asia. This was probably because the travel time cost increase with the rise in income would facilitate a preference for personalized travel modes among travelers. India had the largest rise in vehicle trips from $9.52 \%$ in 2005 to $60.36 \%$ in 2100 . This intense modal shift in India was attributed to the increased per capita income.

Figure 9 also shows heterogeneity across developed and developing regions based on the correlations between GDP per capita and modal share. Modal shares in developed regions, which had a higher GDP per capita, were relatively unchanged, except for slight increases in the share of international aviation. In contrast, modal shares changed dramatically in developing regions where the GDP per capita was low. The modal shares of cars and domestic aviation increased with the rise in GDP per capita, while bus travel showed a sharp decrease in modal share. International aviation, railway, and two wheelers displayed both ascending and descending trends with the increased GDP per capita in developing countries. The changing trends in transport modes other than cars and buses differed from one another. This might be attributable to the different socioeconomic backgrounds and pathways across the 17 regions, such as with regard to population, GDP, and travel costs (fuel price, device price). It was apparent that economic development exerted various influences on the modal shift in different regions. Because car and bus travel accounted for a large proportion of the modal share, the major impacts of economic development on changes in the modal structure in developing regions can be summarized as increased person trips by car and a decline in bus usage. 


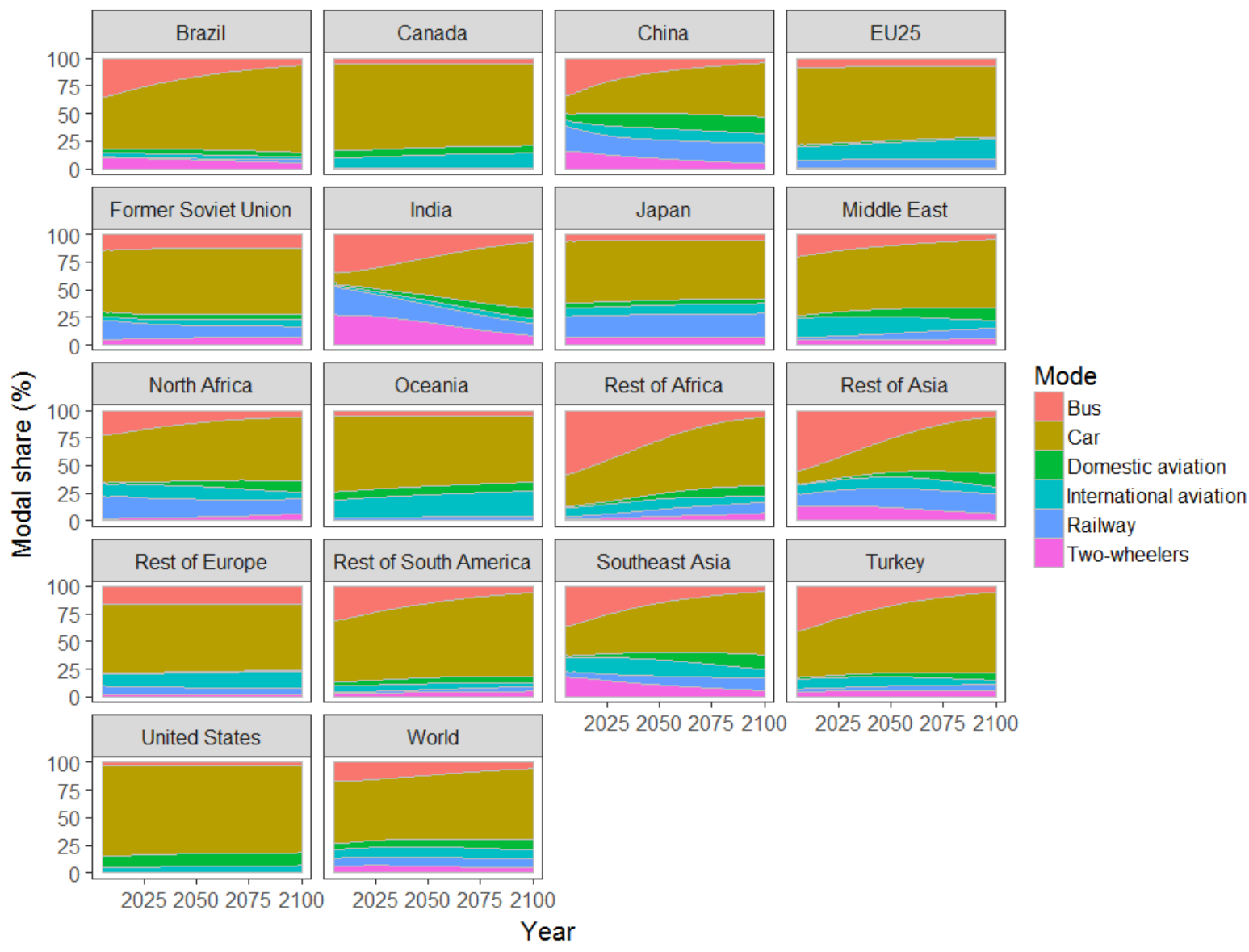

Figure 8. Modal share of different transport options

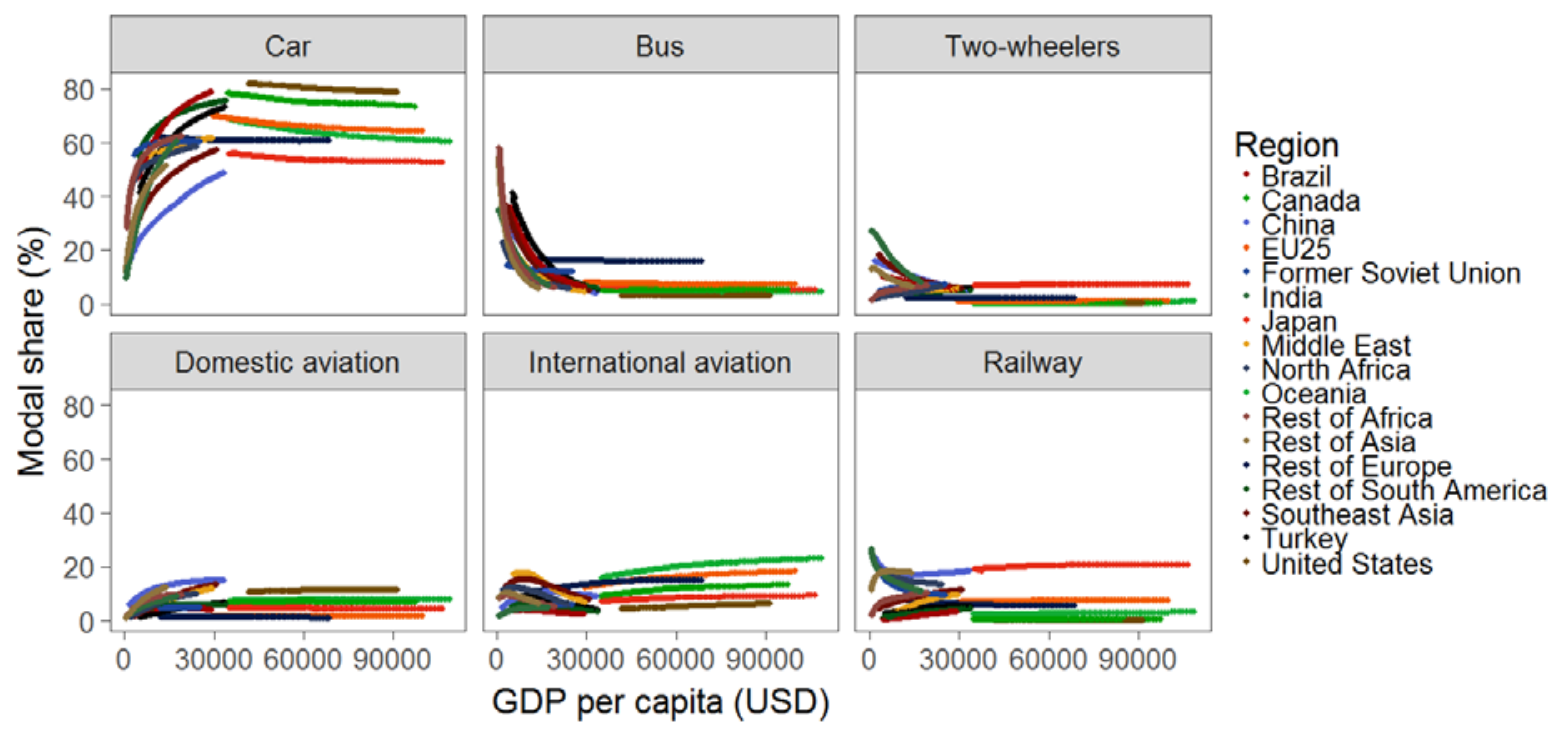

Figure 9. Relationship between GDP per capita and modal share of transport options 
Figure 10 displays the fuel-wise energy consumption generated by global passenger transport. Oil consumed by the transport sector was $44 \mathrm{EJ}$ in 2005 and was projected to be $83 \mathrm{EJ}$ in 2100, accounting for $98.54 \%$ and $77.04 \%$ of all fuel use, respectively. In contrast to the decreasing proportion of oil, the share of electricity and biomass increased to $8.70 \%$ and $11.89 \%$ in 2100 from $0.55 \%$ and zero in 2005 , respectively. Although oil has been replaced by electricity and biomass to some extent, it still plays a dominant role in transport energy consumption. The global GHG emissions produced in the BaU scenario increased steadily from $4 \mathrm{Gt} \mathrm{CO}$ /year in 2005 to 9 Gt $\mathrm{CO}_{2} /$ year in 2100. The contribution of travel modes on GHG emissions proved that cars were the major emission source, followed by aviation.
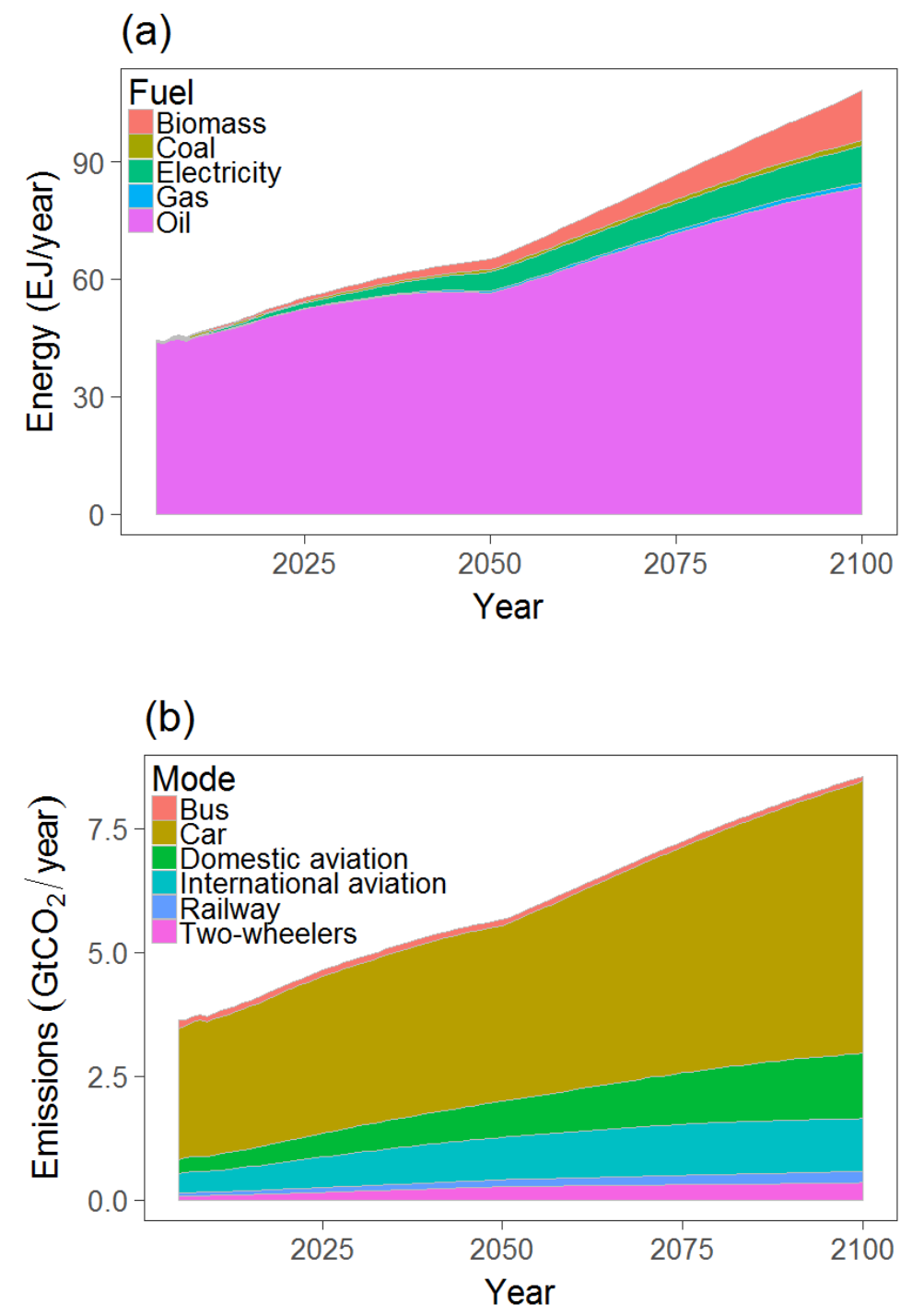

Figure 10. Projected energy use (a) and GHG emissions (b)

\subsection{Mitigation scenario}


For the mitigation scenario, a numerical simulation with the carbon tax policy was able to test how AIM/Transport updates the mitigation cost, because the interplay between the transport sector and the macro-economy can be considered by coupling CGE-Transport modelling. Figure 11 shows the impacts on travel demand, energy consumption, and emission reduction in the carbon tax scenario where a carbon tax is imposed. Travelers tended to cut down on trips with the higher transport cost caused by the carbon tax and, therefore, the global passenger travel demand decreased by 4.38\% in 2010 (Figure 11a). Figure 11b shows that the carbon tax policy reduced oil consumption, while electricity and biomass fuel consumption increased compared with the BaU scenario. This indicates that a carbon tax policy would motivate travelers to choose electrified transport and transport powered by biofuel for personal trips instead of travel modes that relied on oil. Because GHG emissions in the carbon tax scenario were reduced to $4 \mathrm{Gt} \mathrm{CO}_{2}$ /year compared with $9 \mathrm{Gt} \mathrm{CO}_{2}$ /year in the $\mathrm{BaU}$ scenario (Figure 11c), it was found that the goal of GHG emission reduction could be achieved by implementing a carbon tax policy, due to the shift from the use of fossil fuels to electricity and biofuel in the transport sector. Moreover, the emission reduction rate achieved by a carbon tax policy displayed an increasing tendency from around zero to 55.37\%, with the increase in carbon price from 0 to $798 \mathrm{USD} / \mathrm{tCO}_{2}$ in 2100 (Figure 11d), implying that the potential reduction was positively correlated with the carbon price.

(a)

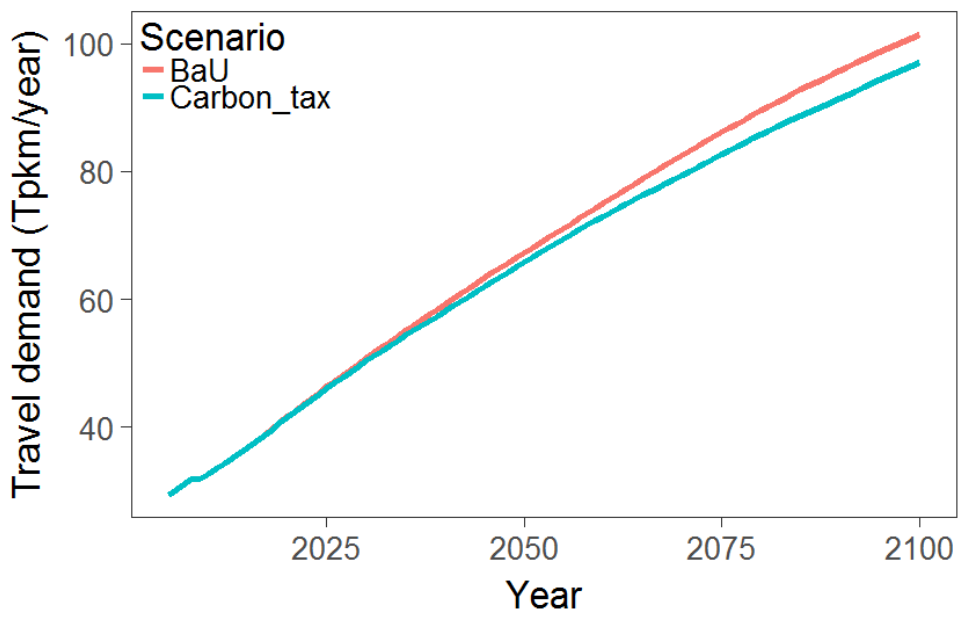


(b)

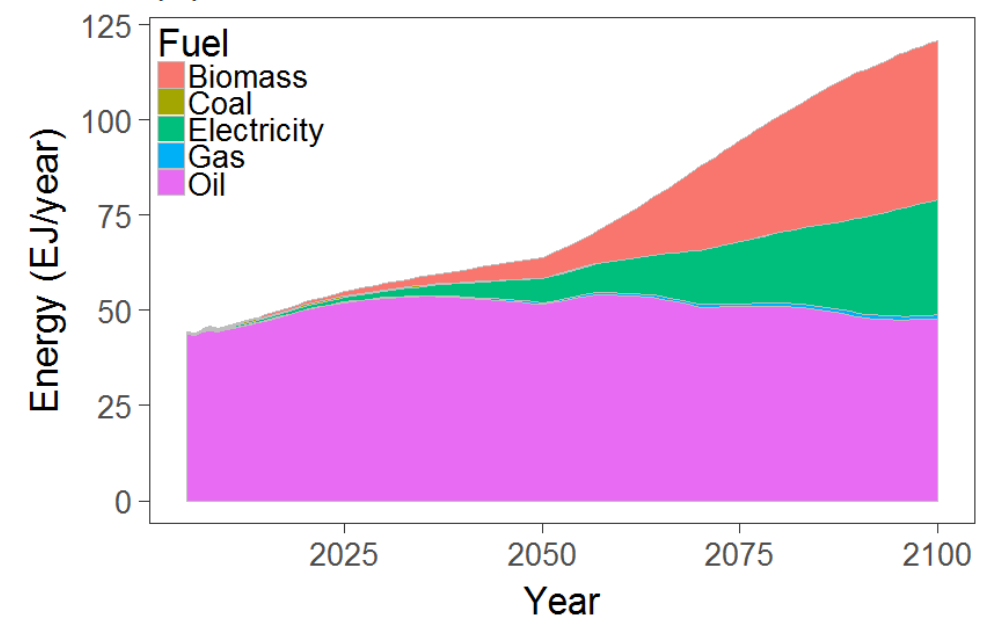

(c)

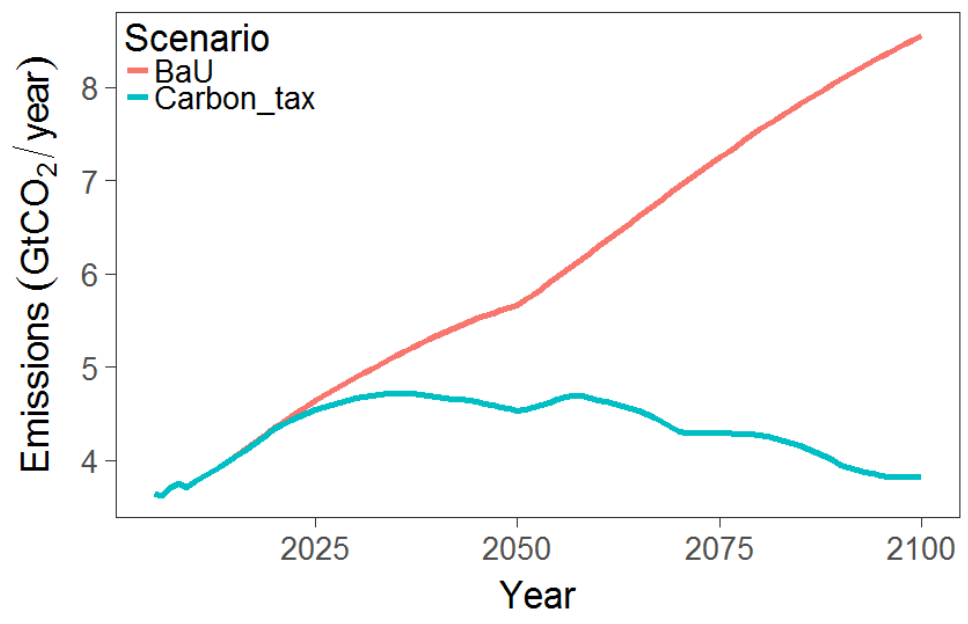

(d)

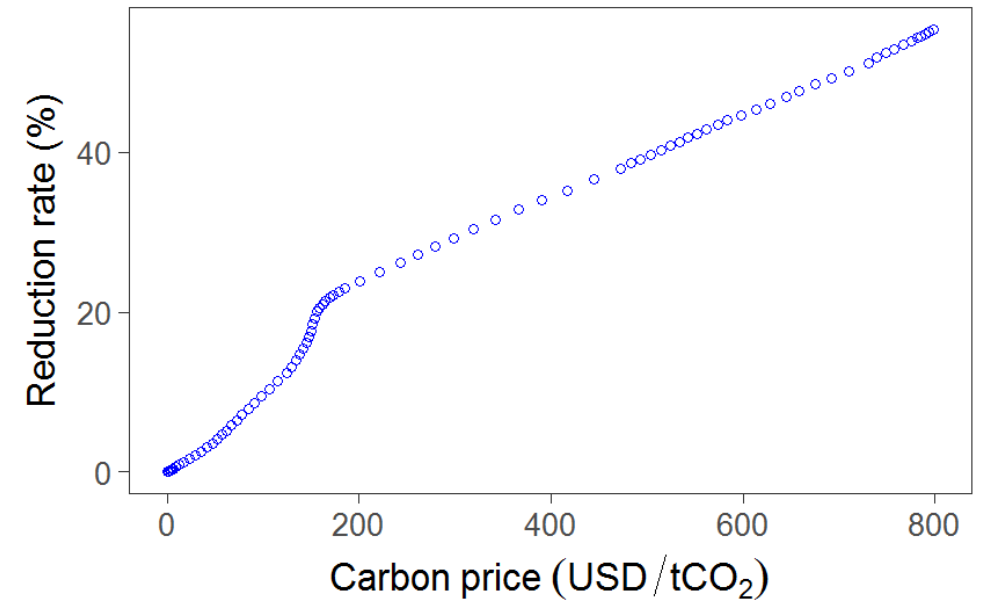




\section{Figure 11. Impacts of carbon tax on: (a) travel demand, (b) energy consumption, (c) GHG emissions, (d) GHG emission reduction rate}

The long-term economic costs and benefits of mitigating climate change over the long term can be estimated using a coupled CGE-Transport model. The carbon tax in 2100 for achieving the target of a two-degree global temperature rise increased from 748 to 798 USD with coupling the transport model. The economic losses are accordant with the changes in carbon price. Without the integration of AIM/CGE and AIM/Transport, the world would experience economic losses equivalent to $1.95 \%$ of annual GDP by 2100. However, if the detailed transport representations provided by AIM/Transport are incorporated, the economic losses would increase to $2.34 \%$ of GDP by 2100 . Figure 12 also shows that the global welfare losses increased from $2.61 \%$ to $3.02 \%$ of the Hicksian equivalent variation (HEV) by 2100 with model integration. The simulation results illustrate that regardless of travel mode and technological details AIM/CGE tends to underestimate the contribution of the transport sector to the overall mitigation cost. As shown here, the transport sector makes an important contribution to global GHG emissions and the de-carbonization of the transport sector deserves more attention.
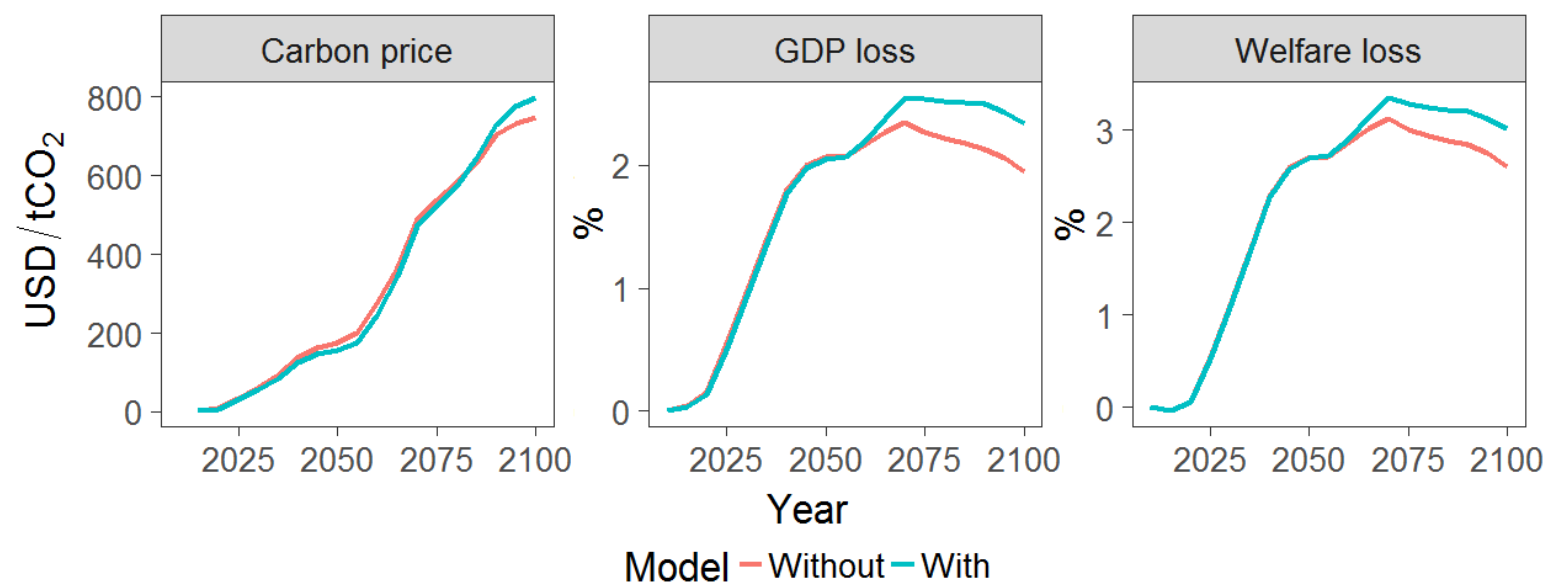

Figure 12. Mitigation cost metrics in the mitigation scenario (carbon price, GDP loss, and welfare losses) with and without coupling Asia-pacific Integrated Model (AIM)/Transport

\section{Discussion}

AIM/Transport coupled with AIM/CGE enabled the global CGE model to consider behavioral and technological issues associated with transport use, and the iterative model integration could handle the dynamic interaction between the transport sector, energy consumption, GHG emissions, and the 
macro-economy. We can answer, therefore, the question of whether the three objectives addressed earlier can be achieved. First, the numerical computation proved the model feasibility and offers a methodology of how to conduct a model integration between AIM/CGE and AIM/Transport. Second, travel demand, modal share, and the energy consumption of the transport sector in AIM/CGE can be updated by the feedback from AIM/Transport, which provides a detailed transport representation for global CGE models. In doing so, mode preference, load factor, vehicle speed, and technological advancement can be incorporated into the CGE model to structure transport scenarios for policy assessment. Third, the coupled model can give balanced consideration to both the technological details of transport and its economic impact. This is a critical point. Existing CGE models incorporated with transport mode decision models are not able to detect how transport behavior and policies would influence the macro-economic system because the feedback from the transport model to the CGE does not occur. This was overcome by our iterative coupling model simulation. To summarize, the coupling of a CGE-Transport model is beneficial for transport planners to analyze how mitigation options would affect travel demand, modal split, transport-related energy consumption, and macro-economic indicators, such as GDP, employment, and social welfare. It is considered that transport policies such as speed control, traffic signal coordination, Intelligent Transport System (ITS), public transport improvement, railway construction, and road network planning, will exert a positive influence on traffic volume, modal shift, and GHG emissions [52-55], but the impacts on other industrial sectors have not been clarified because transport models are rarely appropriately integrated into global CGE models. Our iterative coupling model is a practical tool for investigating how to keep the balance between transport-related GHG emission reduction and economic development.

Compared with the reduction in GHG emissions, the simulation results show that the mitigating effect on passenger travel demand was relatively small in the mitigation scenario, but the carbon tax had a big influence on the technological selection for personal trips, leading to a reduction in transport-related energy consumption and GHG emissions. This was because the carbon tax accounted for a larger proportion of the technology price than the prices of distance, mode, and vehicle size. Technological shifts rather than travel demand were more sensitive to price. It was revealed that the carbon tax was an effective policy tool for the development of low-carbon transport because the technology mix is sensitive to the carbon tax and travelers are motivated to choose low-carbon technologies and fuels such as electricity, gas, and biomass for personal trips. Because global travel demand will not be significantly depressed by the carbon tax, the superabundant worldwide traffic volumes will generate excessive congestion, which leads to loss of working time, redundant emissions, and a decline in social welfare. It is therefore necessary to devise alternative policies that could prevent inordinate growth in global travel 
demand, although the effectiveness of the carbon tax policy for fossil fuel emission reduction has been confirmed. Another key finding was that the mitigation cost could be modified with detailed information regarding the transport sector. The underestimation of GDP and welfare loss by AIM/CGE without detailed transport information indicates that appropriate model representation is needed in the transport sector. In the meantime, such treatment enables a broader sense of policy analysis, which might decrease macroeconomic loss (e.g., transport specific policies). Not only does the transport sector have considerable potential for emission reduction, but a low-carbon transport policy could also help to limit the economic losses caused by climate change mitigation.

There are still many limitations of the model that need to be addressed in the future. In AIM/CGE, international aviation is included in the international trade, although the model integration of AIM/CGE and AIM/Transport only focuses on the travel modes of car, bus, two wheelers, domestic aviation, and railways, but excludes international aviation. Therefore, the convergence is reached when AIM/CGE and AIM/Transport consume some quantity of energy for car, bus, two wheelers, domestic aviation, and railway, regardless of whether the energy consumed by international aviation is the same. In this study, we did not consider non-motorized travel modes like walking and cycling due to data limitations. Because the non-motorized modes are carbon neutral, further research is required to determine which policies could facilitate the use of non-motorized modes and estimate the mitigation potential of a modal shift from motorized traffic to non-motorized modes. In addition, heterogeneity among travelers is not taken into consideration explicitly in the AIM/Transport model, which is important for realistically estimating the mode choice probability. Another limitation is that AIM/Transport considers only passenger transport, which is closely related to traveler behavior and transport policies, but freight transport is also responsible for GHG emissions. Global transport-related GHG emissions have been projected by several IAMs [20, 39, 41, 56, 57]. As shown in Figure 13, all of these models project total direct GHG emissions for the baseline scenario to be around $6 \mathrm{Gt} \mathrm{CO}_{2}$ in 2050, and even the GHG emissions projected by TIMER and IEA peak at more than 8 and $10 \mathrm{Gt} \mathrm{CO}_{2}$ /year, respectively [40]. As a result of economic growth and technological improvement, we assumed that all travel modes in our model will manifest significant fuel efficiency improvements from 2005 to 2050. AIM/Transport estimates relatively higher shares of biomass and electricity than other models. Due to the differences in energy intensity and fuel structure, AIM/Transport projects a lower GHG emission trajectory. 


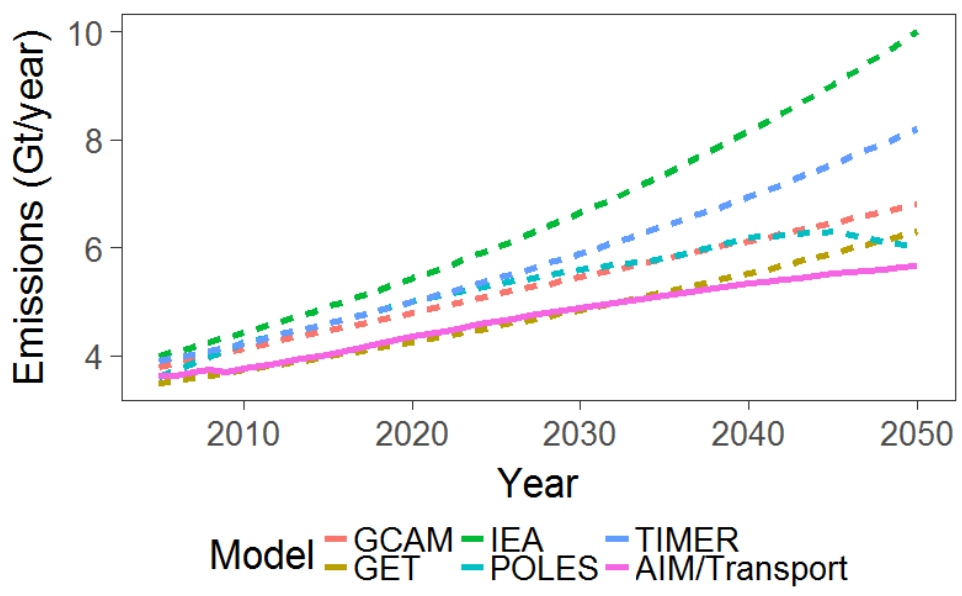

Figure 13. Global passenger transport-related GHG emission trajectories projected by different models

\section{Conclusions}

This paper proposes the coupling of a new passenger transport model, AIM/Transport, and AIM/CGE. There were three main conclusions. First, the methodology for coupling the CGE-Transport model was demonstrated to incorporate the travel mode and transport technological details in AIM/CGE, to enrich the transport representation. The numerical computation illustrated that the coupled model can achieve a convergence, indicating that integration of the transport model and global CGE was possible. Second, the simulation results show that travel demand, energy consumption, and GHG emissions differ among regions and transport modes. Cars and oil still play dominant roles in energy consumption and GHG emissions. A carbon tax would have a significant influence on the technology and fuel choice, which helps reduce GHG emissions and mitigate global warming. Third, an analysis of the interplay between the transport sector and macro-economy becomes feasible by using the coupling model. Changes in mitigation costs with the feedback from AIM/Transport revealed that the importance of the transport sector was underestimated by AIM/CGE. The de-carbonization of the transport sector deserves further investigation because the simulation results of the coupling model showed a significant contribution by the transport sector to global climate change mitigation.

Although the discussion above clearly demonstrates that AIM/Transport still has limitations, this model can be linked with a global CGE model; thus, it is possible to chart, briefly, a roadmap for such applications. An interesting theme is how the transport patterns and policies affect the mitigation potential and cost. In this study, only a carbon tax scenario was simulated, but such a coupling model would also 
allow the impacts of transport policies such as mass transit systems and high speed railways to be determined, because the dynamic interaction between the transport sector and macro-economy becomes possible using the coupling CGE-Transport model. Furthermore, endogenous congestion and transport infrastructure was suppressed in the study. The model could easily be extended to introduce a congestion travel time function and thus make the congestion explicit and endogenous. Such an extended model would provide an understanding of the dynamic effects and interaction of traffic congestion, travel time, loss of working time, energy consumption, employment, and economic development.

\section{Acknowledgement}

This study was supported by the Global Environmental Research Fund S12-3, and S14-5 of the Ministry of Environment of Japan and the Japan Society for the Promotion of Science (JSPS) KAKENHI Grant Number JP16K18177. The authors are grateful for the receipt of these funds.

\section{References}

[1] IEA. CO2 Emissions from Fuel Combustion Highlights 2015. Paris: International Energy Agency; 2015. [2] IEA. Transport, Energy and CO2: Moving toward Sustainability. Paris: International Energy Agency; 2009.

[3] Gambhir A, Tong D, Martinez Botas R. Reducing China's road transport sector CO 2 emissions to 2050: Technologies, costs and decomposition analysis. Appl Energy. 2015;157:905-17.

[4] Sims R, Schaeffer R, Creutzig F, al. e. Transport. In: Climate Change 2014: Mitigation of Climate Change. Contribution of Working Group III to the Fifth Assessment Report of the Intergovernmental Panel on Climate Change. Cambridge, United Kingdom and New York, NY, USA2014.

[5] Chung W, Zhou G. A study of energy efficiency of transport sector in China from 2003 to 2009. Appl Energy. 2013;112:1066-77.

[6] Azar C, Lindgren K, Andersson BA. Global energy scenarios meeting stringent CO2 constraints cost-effective fuel choices in the transportation sector. Energy Policy. 2003;31:961-76.

[7] Pietzcker RC, Longden T, Chen WY, Fu S, Kriegler E, Kyle P, et al. Long-term transport energy demand and climate policy: Alternative visions on transport decarbonization in energy-economy models. Energy. 2014;64:95-108.

[8] Brand C, Goodman A, Ogilvie D. Evaluating the impacts of new walking and cycling infrastructure on carbon dioxide emissions from motorized travel: A controlled longitudinal study. Appl Energy. 2014;128:284-95.

[9] Lindfeldt E, Saxe M, Magnusson M, Mohseni F. Strategies for a road transport system based on renewable resources - The case of an import-independent Sweden in 2025. Appl Energy. 2010;87:1836-45.

[10] Pongthanaisawan J, Sorapipatana C. Greenhouse gas emissions from Thailand's transport sector: Trends and mitigation options. Appl Energy. 2013;101:288-98.

[11] Wang Z, Liu W. Determinants of CO 2 emissions from household daily travel in Beijing, China: Individual travel characteristic perspectives. Appl Energy. 2015;158:292-9.

[12] Calvin K, Bond-Lamberty B, Clarke L, Edmonds J, Eom J, Hartin C, et al. The SSP4: A world of deepening inequality. Global Environmental Change. 2016. 
[13] Fricko O, Havlik P, Rogelj J, Klimont Z, Gusti M, Johnson N, et al. The marker quantification of the Shared Socioeconomic Pathway 2: A middle-of-the-road scenario for the 21st century. Global Environmental Change. 2016.

[14] Fujimori S, Hasegawa T, Masui T, Takahashi K, Herran DS, Dai H, et al. SSP3: AIM implementation of Shared Socioeconomic Pathways. Global Environmental Change. 2016.

[15] Kriegler E, Bauer N, Popp A, Humpenöder F, Leimbach M, Strefler J, et al. Fossil-fueled development (SSP5): An energy and resource intensive scenario for the 21st century. Global Environmental Change. 2016.

[16] van Vuuren DP, Stehfest E, Gernaat DEHJ, Doelman JC, van den Berg M, Harmsen M, et al. Energy, land-use and greenhouse gas emissions trajectories under a green growth paradigm. Global Environmental Change. 2016.

[17] Oxley T, Valiantis M, Elshkaki A, ApSimon HM. Background, Road and Urban Transport modelling of Air quality Limit values (The BRUTAL model). Environmental Modelling \& Software. 2009;24:1036-50.

[18] Akashi O, Hanaoka T. Technological feasibility and costs of achieving a $50 \%$ reduction of global GHG emissions by 2050: mid- and long-term perspectives. Sustain Sci. 2012;7:139-56.

[19] Akashi O, Hijioka Y, Masui T, Hanaoka T, Kainuma M. GHG emission scenarios in Asia and the world: The key technologies for significant reduction. Energ Econ. 2012;34:S346-S58.

[20] Fulton L, Cazzola P, Cuenot F. IEA Mobility Model (MoMo) and its use in the ETP 2008. Energy Policy. 2009;37:3758-68.

[21] Krzyzanowski DA, Kypreos S, Barreto L. Supporting hydrogen based transportation: case studies with Global MARKAL Model. Computational Management Science. 2008;5:207-31.

[22] Fujimori S, Kainuma M, Masui T, Hasegawa T, Dai $H$. The effectiveness of energy service demand reduction: A scenario analysis of global climate change mitigation. Energy Policy. 2014;75:379-91.

[23] Fujimori S, Masui T, Matsuoka Y. Gains from emission trading under multiple stabilization targets and technological constraints. Energ Econ. 2015;48:306-15.

[24] Fujimori S, Mosui T, Matsuoka Y. Development of a global computable general equilibrium model coupled with detailed energy end-use technology. Appl Energy. 2014;128:296-306.

[25] Hasegawa T, Fujimori S, Shin Y, Takahashi K, Masui T, Tanaka A. Climate Change Impact and Adaptation Assessment on Food Consumption Utilizing a New Scenario Framework. Environ Sci Technol. 2014;48:438-45.

[26] Hasegawa T, Fujimori S, Shin Y, Tanaka A, Takahashi K, Masui T. Consequence of Climate Mitigation on the Risk of Hunger. Environ Sci Technol. 2015;49:7245-53.

[27] Hasegawa T, Fujimori S, Takahashi K, Masui T. Scenarios for the risk of hunger in the twenty-first century using Shared Socioeconomic Pathways. Environ Res Lett. 2015;10.

[28] Thepkhun P, Limmeechokchai B, Fujimori S, Masui T, Shrestha RM. Thailand's Low-Carbon Scenario 2050: The AIM/CGE analyses of CO2 mitigation measures. Energy Policy. 2013;62:561-72.

[29] Ashiabor S, Baik H, Trani A. Logit models for forecasting nationwide intercity travel demand a in the United States. Transp Res Record. 2007:1-12.

[30] Scheiner J. Interrelations between travel mode choice and trip distance: trends in Germany 1976-2002. J Transp Geogr. 2010;18:75-84.

[31] Wen CH, Koppelman FS. The generalized nested logit model. Transport Res B-Meth. 2001;35:627-41.

[32] Ben-Akiva M, Bolduc D, Bradley M. Estimation of travel choice models with randomly distributed values of time. Transp Res Record. 1993:88-97.

[33] Horne M, Jaccard M, Tiedemann K. Improving behavioral realism in hybrid energy-economy models using discrete choice studies of personal transportation decisions. Energ Econ. 2005;27:59-77. 
[34] Lin ZH, Greene DL. Assessing Energy Impact of Plug-In Hybrid Electric Vehicles Significance of Daily Distance Variation over Time and Among Drivers. Transp Res Record. 2011:99-106.

[35] Rivers N, Jaccard M. Useful models for simulating policies to induce technological change. Energy Policy. 2006;34:2038-47.

[36] Yeh S, Mishra GS, Fulton L, Kyle P, McCollum DL, Miller J, et al. Detailed assessment of global transport-energy models' structures and projections. Transportation Research Part D: Transport and Environment.

[37] Daly HE, Ramea K, Chiodi A, Yeh S, Gargiulo M, Gallachoir BO. Incorporating travel behaviour and travel time into TIMES energy system models. Appl Energy. 2014;135:429-39.

[38] Girod B, van Vuuren DP, de Vries B. Influence of travel behavior on global CO2 emissions. Transport Res a-Pol. 2013;50:183-97.

[39] Girod B, van Vuuren DP, Deetrnan S. Global travel within the 2 degrees C climate target. Energy Policy. 2012;45:152-66.

[40] Girod B, van Vuuren DP, Grahn M, Kitous A, Kim SH, Kyle P. Climate impact of transportation A model comparison. Clim Change. 2013;118:595-608.

[41] Kyle P, Kim SH. Long-term implications of alternative light-duty vehicle technologies for global greenhouse gas emissions and primary energy demands. Energy Policy. 2011;39:3012-24.

[42] McCollum DL, Wilson C, Pettifor H, Ramea K, Krey V, Riahi K, et al. Improving the behavioral realism of global integrated assessment models: An application to consumers' vehicle choices. Transportation Research Part D: Transport and Environment. 2016.

[43] Waisman HD, Guivarch C, Lecocq F. The transportation sector and low-carbon growth pathways: modelling urban, infrastructure, and spatial determinants of mobility. Clim Policy. 2013;13:106-29.

[44] Karkatsoulis P, Siskos P, Paroussos L, Capros P. Simulating deep CO2 emission reduction in transport in a general equilibrium framework: The GEM-E3T model. Transportation Research Part D: Transport and Environment.

[45] Zhang HJ, Chen WY, Huang WL. TIMES modelling of transport sector in China and USA: Comparisons from a decarbonization perspective. Appl Energy. 2016;162:1505-14.

[46] Ó Broin E, Guivarch C. Transport infrastructure costs in low-carbon pathways. Transportation Research Part D: Transport and Environment. 2016.

[47] Fujimori S, Masui T, Matsuoka Y. AIM/CGE [basic] manual. Discussion paper series. Tsukuba: National Institute for Environmental Studies; 2012.

[48] McNally MG. The Four-Step Model. Handbook of Transport Modelling (Handbooks in Transport, Volume 1)2007. p. 35-53.

[49] Mishra SG, Kyle P, Teter J. Transportation Module of Global Change Assessment Model (GCAM): Model Documentation. California, USA: Institute of Transportation Studies, University of California, Davis.; 2013.

[50] Fujimori S, Dai HC, Masui T, Matsuoka Y. Global energy model hindcasting. Energy. 2016;114:293-301.

[51] IIASA. SSP Database. In: IIASA, editor.2015.

[52] Madireddy M, De Coensel B, Can A, Degraeuwe B, Beusen B, De Vlieger I, et al. Assessment of the impact of speed limit reduction and traffic signal coordination on vehicle emissions using an integrated approach. Transport Res D-Tr E. 2011;16:504-8.

[53] Zhou Y, Tupper L, Chowdhury M, Klotz L. Green Credits Versus Environmentally Sustainable Traffic Operations Comparison of Contributions to Energy and Emissions Reductions. Transp Res Record. 2010:103-11.

[54] De Coensel B, Can A, Degraeuwe B, De Vlieger I, Botteldooren D. Effects of traffic signal coordination on noise and air pollutant emissions. Environmental Modelling \& Software. 2012;35:74-83. 
[55] Kolosz B, Grant-Muller S, Djemame K. Modelling uncertainty in the sustainability of Intelligent Transport Systems for highways using probabilistic data fusion. Environmental Modelling \& Software. 2013;49:78-97.

[56] Grahn M, Azar C, Williander MI, Anderson JE, Mueller SA, Wallington TJ. Fuel and Vehicle Technology Choices for Passenger Vehicles in Achieving Stringent CO2 Targets: Connections between Transportation and Other Energy Sectors. Environ Sci Technol. 2009;43:3365-71.

[57] Kitous A, Criqui P, Bellevrat E, Chateau B. Transformation Patterns of the Worldwide Energy System - Scenarios for the Century with the POLES Model. Energ J. 2010;31:49-82. 